\title{
Cardiovascular effects of sodium glucose cotransporter 2 inhibitors
}

This article was published in the following Dove Press journal: Diabetes, Metabolic Syndrome and Obesity:Targets and Therapy

\author{
Tricia Santos Cavaiola \\ Jeremy Pettus \\ Division of Endocrinology and \\ Metabolism, University of California \\ San Diego, San Diego, CA, USA
}

Correspondence: Tricia Santos Cavaiola Division of Endocrinology and Metabolism, University of California San Diego, 3350 La Jolla Village Drive, IIIG, San Diego, CA 92161, USA

$\mathrm{Tel}+\mathrm{I} 6195436303$

Fax + I 619 5437352

Email tksantos@ucsd.edu

\begin{abstract}
As the first cardiovascular (CV) outcome trial of a glucose-lowering agent to demonstrate a reduction in the risk of CV events in patients with type 2 diabetes mellitus (T2DM), the EMPAgliflozin Removal of Excess Glucose: Cardiovascular OUTCOME Event Trial in Type 2 Diabetes Mellitus Patients (EMPA-REG OUTCOME ${ }^{\circledR}$ ) trial, which investigated the sodium glucose cotransporter 2 (SGLT2) inhibitor empagliflozin, has generated great interest among health care professionals. CV outcomes data for another SGLT2 inhibitor, canagliflozin, have been published recently in the CANagliflozin CardioVascular Assessment Study (CANVAS) Program, as have $\mathrm{CV}$ data from the retrospective real-world study Comparative Effectiveness of Cardiovascular Outcomes in New Users of Sodium-Glucose Cotransporter-2 Inhibitors (CVD-REAL), which compared SGLT2 inhibitors with other classes of glucose-lowering drugs. This review discusses the results of these three studies and, with a focus on EMPA-REG OUTCOME, examines the possible mechanisms by which SGLT2 inhibitors may reduce CV risk in patients with T2DM.
\end{abstract}

Keywords: canagliflozin, cardiovascular outcomes, dapagliflozin, empagliflozin, mechanisms, sodium glucose cotransporter 2 inhibitors

\section{Introduction}

Cardiovascular disease (CVD) is the leading cause of morbidity and mortality in individuals with diabetes, and reducing CVD risk is a key treatment consideration. ${ }^{1}$ Intensive blood glucose control to reduce hyperglycemia decreases the risk of microvascular complications in type 2 diabetes mellitus (T2DM); ${ }^{2,3}$ however, the relationship between glucose lowering and the risk of macrovascular disease is less straightforward, as demonstrated by data from trials such as UK Prospective Diabetes Study (UKPDS), Action to Control Cardiovascular Risk in Diabetes (ACCORD), Action in Diabetes and Vascular Disease - Preterax and Diamicron Modified Release Controlled Evaluation (ADVANCE), and Veterans Affairs Diabetes Trial (VADT). ${ }^{2-8}$ Indeed, higher rates of all-cause and cardiovascular (CV) mortality associated with intensive blood glucose lowering were reported during ACCORD, ${ }^{5}$ although the contribution of hypoglycemia is debated. ${ }^{9}$ Until 2008, clinical trials of drug therapies for T2DM typically focused on the glucose-lowering ability, via reductions in glycated hemoglobin (HbA1c), and studies of longer term $\mathrm{CV}$ outcomes were not required for regulatory approval in the US. However, following the 2007 publication of CV safety issues in patients with T2DM related to the use of rosiglitazone, ${ }^{10}$ the US Food and Drug Administration (FDA) issued guidance that required all glucose-lowering agents for the treatment of T2DM to undergo a thorough assessment on major adverse CV events (MACE), 
mandating that such agents take part in a CV outcome trial (CVOT) in diabetes patients with high CV risk. ${ }^{11}$ As the purpose of the CVOT is to assess drug-specific CV safety independent of glucose-lowering efficacy, background glucose-lowering agents (other than the class of active comparator being investigated) are permitted in all treatment arms, per the standard of care. ${ }^{12}$ Data from a number of CVOTs in glucose-lowering agents have been completed (Table 1), ${ }^{13-26}$ and others are underway (Table 2). ${ }^{27,28}$ Results from several CVOTs in glucose-lowering agents have demonstrated CV safety and met the criteria for non-inferiority versus placebo, but have not shown superiority, namely,

Table I Completed CV outcome trials of glucose-lowering drugs in patients with T2DM

\begin{tabular}{|c|c|c|c|c|c|}
\hline $\begin{array}{l}\text { Trial name } \\
\text { (publication year) }\end{array}$ & Major inclusion criteria & $\begin{array}{l}\text { Number } \\
\text { of patients } \\
\text { randomized }\end{array}$ & $\begin{array}{l}\text { Median } \\
\text { follow-up, } \\
\text { years } \\
\end{array}$ & Intervention & Primary outcome data \\
\hline \multicolumn{6}{|l|}{ DPP-4 inhibitors } \\
\hline $\begin{array}{l}\text { SAVOR-TIMI } 53 \\
(2013)^{13}\end{array}$ & $\begin{array}{l}\geq 40 \text { years + history of } \\
\text { established CVD; males } \geq 55 \\
\text { years or females } \geq 60 \text { years } \\
\text { + risk factors for vascular } \\
\text { disease }\end{array}$ & 16,492 & 2.1 & $\begin{array}{l}\text { Saxagliptin versus } \\
\text { placebo }\end{array}$ & $\begin{array}{l}\text { Composite: CV death, non-fatal } \\
\text { MI, or non-fatal ischemic stroke; } \\
\text { HR I.00 ( } 95 \% \mathrm{Cl}: 0.89, \mathrm{I} . \mathrm{I}) \text {; } \\
p=0.99 \text { for superiority; } p<0.00 \mathrm{I} \\
\text { for non-inferiority }\end{array}$ \\
\hline EXAMINE $(2013)^{14}$ & $\begin{array}{l}\text { Acute coronary event within } \\
\text { previous } 15-90 \text { days }\end{array}$ & 5380 & 1.8 & $\begin{array}{l}\text { Alogliptin versus } \\
\text { placebo }\end{array}$ & $\begin{array}{l}\text { Composite: CV death, non-fatal } \\
\text { MI, or non-fatal stroke; HR } 0.96 \\
\text { (upper bound of one-sided } \\
\text { repeated } \mathrm{Cl}: \text { I.I6); } p<0.00 \text { I for } \\
\text { non-inferiority }\end{array}$ \\
\hline $\operatorname{TECOS}(2014)^{15}$ & $\begin{array}{l}\mathrm{HbAlc} 6.5 \%-8.0 \% ; \geq 50 \\
\text { years; established CVD }\end{array}$ & $|4,67|$ & 3.0 & $\begin{array}{l}\text { Sitagliptin versus } \\
\text { placebo }\end{array}$ & $\begin{array}{l}\text { Composite: CV death, non- } \\
\text { fatal MI, non-fatal stroke, or } \\
\text { hospitalization for UA; HR } 0.98 \\
(95 \% \mathrm{Cl} \text { : } 0.88, \text { I.09); } p<0.00 \text { I for } \\
\text { non-inferiority }\end{array}$ \\
\hline \multicolumn{6}{|c|}{ GLP-I receptor agonists } \\
\hline ELIXA $(2015)^{16}$ & $\begin{array}{l}\text { HbAlc } 5.5 \%-1 \mathrm{I} .0 \% \text {; acute } \\
\text { coronary event } \leq 180 \text { days } \\
\text { prior to screening }\end{array}$ & 6068 & 2.1 & $\begin{array}{l}\text { Lixisenatide versus } \\
\text { placebo }\end{array}$ & $\begin{array}{l}\text { Composite: CV death, non- } \\
\text { fatal MI, non-fatal stroke, or } \\
\text { hospitalization for UA; HR I.02 } \\
(95 \% \mathrm{Cl}: 0.89, \mathrm{I} . \mathrm{I7}) ; p=0.8 \mathrm{I} \text { for } \\
\text { superiority; } p<0.00 \text { I for non- } \\
\text { inferiority }\end{array}$ \\
\hline LEADER $(2016)^{17}$ & $\begin{array}{l}\mathrm{HbAlc} \geq 7.0 \% ; \geq 50 \text { years }+ \\
\mathrm{CVD} ; \geq 60 \text { years }+\geq \mathrm{I} \mathrm{CV} \\
\text { risk factor }\end{array}$ & 9340 & 3.8 & $\begin{array}{l}\text { Liraglutide versus } \\
\text { placebo }\end{array}$ & $\begin{array}{l}\text { Composite: CV death, non-fatal } \\
\text { MI, or non-fatal stroke; } \\
\text { HR } 0.87 \text { ( } 95 \% \text { Cl: } 0.78,0.97) \\
p=\mathbf{0 . 0 I} \text { for superiority; } \\
p<0.00 \text { I for non-inferiority }\end{array}$ \\
\hline SUSTAIN-6 (2016) & $\begin{array}{l}\mathrm{HbAlc} \geq 7.0 \% ; \geq 50 \text { years }+ \\
\mathrm{CVD} ; \geq 60 \text { years }+\geq \mathrm{I} \mathrm{CV} \\
\text { risk factor }\end{array}$ & 3297 & 2.1 & $\begin{array}{l}\text { Semaglutide } 0.5 \mathrm{mg} \\
\text { versus semaglutide } \\
1.0 \mathrm{mg} \text { versus placebo }\end{array}$ & $\begin{array}{l}\text { Composite: CV death, non-fatal } \\
\text { MI, or non-fatal stroke; } \\
\text { HR } 0.74 \text { ( } 95 \% \text { Cl: } 0.58,0.95) \\
\mathbf{p}=\mathbf{0 . 0 2} \text { for superiority; } \\
p<0.00 \text { I for non-inferiority }\end{array}$ \\
\hline EXSCEL $(2017)^{19}$ & $\begin{array}{l}\text { HbAlc }>6.5 \% \text {; } 40 \text { years + } \\
\text { CVD history }\end{array}$ & 14,752 & 3.2 & $\begin{array}{l}\text { Subcutaneous } \\
\text { injections of } \\
\text { extended-release } \\
\text { exenatide } 2 \mathrm{mg} \\
\text { versus placebo (once } \\
\text { weekly) }\end{array}$ & $\begin{array}{l}\text { Composite: CV death, non-fatal } \\
\text { MI, or non-fatal stroke; HR 0.9I } \\
\text { ( } 95 \% \mathrm{Cl}: 0.83,1.00) ; p=0.06 \text { for } \\
\text { superiority; } p<0.00 \text { I for non- } \\
\text { inferiority }\end{array}$ \\
\hline $\begin{array}{l}\text { FREEDOM-CVO } \\
\text { (NCTOI455896) }\end{array}$ & $\begin{array}{l}\text { HbAlc }>6.5 \% \text {; } 40 \text { years + } \\
\text { CVD history }\end{array}$ & 4156 & & $\begin{array}{l}\text { ITCA } 650 \\
\text { (continuous } \\
\text { subcutaneous } \\
\text { exenatide } 60 \mathrm{mcg} / \\
\text { day) versus placebo }\end{array}$ & $\begin{array}{l}\text { Composite: CV death, MI, stroke, } \\
\text { or hospitalization for UA (data } \\
\text { not published; study met primary } \\
\text { and secondary endpoints by } \\
\text { demonstrating FDA-required } \\
\text { non-inferiority for preapproval } \\
\text { CV safety }{ }^{20} \text { ) }\end{array}$ \\
\hline
\end{tabular}


Table I (Continued)

\begin{tabular}{|c|c|c|c|c|c|}
\hline $\begin{array}{l}\text { Trial name } \\
\text { (publication year) }\end{array}$ & Major inclusion criteria & $\begin{array}{l}\text { Number } \\
\text { of patients } \\
\text { randomized }\end{array}$ & $\begin{array}{l}\text { Median } \\
\text { follow-up, } \\
\text { years }\end{array}$ & Intervention & Primary outcome data \\
\hline \multicolumn{6}{|l|}{ Insulin } \\
\hline DEVOTE $(2017)^{21}$ & $\begin{array}{l}\mathrm{HbAlc} \geq 7.0 \% \text { or }<7.0 \% \\
\text { with basal insulin } 20 \mathrm{U} / \text { day; } \\
\geq 50 \text { years }+\mathrm{CVD} \text { or renal } \\
\text { disease; } \geq 60 \text { years }+\mathrm{CV} \text { risk } \\
\text { factors }\end{array}$ & 7637 & $\sim 2.0$ & $\begin{array}{l}\text { Insulin degludec } \\
\text { versus insulin glargine }\end{array}$ & $\begin{array}{l}\text { Composite: CV death, non-fatal } \\
\text { MI, or non-fatal stroke; degludec } \\
\text { versus glargine; HR } 0.9 \mathrm{I}(95 \% \mathrm{Cl} \text { : } \\
0.78, \text { I.06); } p<0.00 \text { I for non- } \\
\text { inferiority in a one-sided test }\end{array}$ \\
\hline \multicolumn{6}{|l|}{$\begin{array}{l}\text { PPAR-gamma } \\
\text { agonists }\end{array}$} \\
\hline TOSCA.IT $(2017)^{22}$ & $\begin{array}{l}\mathrm{HbAlc} \geq 7.0 \% \text { and } \leq 9.0 \% \\
\text { metformin monotherapy }\end{array}$ & 3028 & 4.75 & $\begin{array}{l}\text { Pioglitazone versus } \\
\text { sulfonylurea }\end{array}$ & $\begin{array}{l}\text { Composite: death, non-fatal } \\
\text { MI, non-fatal stroke or urgent } \\
\text { coronary revascularization; } \\
\text { HR } 0.96 \text { ( } 95 \% \text { Cl: } 0.74, \text { I.26); } \\
p=0.79\end{array}$ \\
\hline \multicolumn{6}{|l|}{ SGLT2 inhibitors } \\
\hline $\begin{array}{l}\text { EMPA-REG } \\
\text { OUTCOME }(2015)^{23}\end{array}$ & $\begin{array}{l}\text { HbAlc } 7.0 \%-9.0 \% \text { (if drug } \\
\text { naïve) or } 7.0 \%-10.0 \% \text { (if } \\
\text { receiving stable glucose- } \\
\text { lowering medication }>12 \\
\text { weeks pre-randomization); } \\
\text { established CVD }\end{array}$ & 7020 & 3.1 & $\begin{array}{l}\text { Empagliflozin } 10 \mathrm{mg} \\
\text { versus empagliflozin } \\
25 \mathrm{mg} \text { versus } \\
\text { placebo (analyzed as } \\
\text { empagliflozin pooled } \\
\text { vs placebo) }\end{array}$ & $\begin{array}{l}\text { Composite: CV death, non-fatal } \\
\text { MI, or non-fatal stroke; } \\
\text { HR } 0.86 \text { ( } 95.02 \% \text { Cl: } 0.74,0.99) \\
p=0.04 \text { for superiority; } \\
p<0.00 \text { I for non-inferiority }\end{array}$ \\
\hline $\begin{array}{l}\text { CANVAS Program } \\
(2017)^{24}(\text { CANVAS }+ \\
\text { CANVAS-R) }\end{array}$ & $\begin{array}{l}\mathrm{HbAlc} 7.0 \%-10.5 \% ; \geq 30 \\
\text { years history of CVD, or } \geq 50 \\
\text { years high risk of CVD }\end{array}$ & $\begin{array}{l}10,142 \\
\text { (CANVAS } 4330 \\
+ \text { CANVAS-R } \\
5812 \text { ) }\end{array}$ & 2.4 & $\begin{array}{l}\text { Canagliflozin } 100 \mathrm{mg} \\
\text { versus canagliflozin } \\
300 \mathrm{mg} \text { versus } \\
\text { placebo }\end{array}$ & $\begin{array}{l}\text { Composite: CV death, non-fatal } \\
\text { MI, and non-fatal stroke; } \\
\text { HR } 0.86 \text { ( } 95 \% \mathrm{Cl}: 0.75,0.97) \\
\mathbf{p}=\mathbf{0 . 0 2} \text { for superiority; } \\
p<0.00 \text { I for non-inferiority }\end{array}$ \\
\hline CVD-REAL* $(2017)^{25}$ & $\begin{array}{l}\text { T2DM; new users of SGLT2 } \\
\text { inhibitors or other GLD }\end{array}$ & $\begin{array}{l}\text { (Not } \\
\text { randomized; } \\
\text { observational) } \\
309,056\end{array}$ & $\begin{array}{l}\text { Retrospective } \\
\text { registries study }\end{array}$ & $\begin{array}{l}\text { SGLT2 inhibitors } \\
\text { versus other classes } \\
\text { of GLD }\end{array}$ & $\begin{array}{l}\text { Hospitalization for heart failure; } \\
\text { HR 0.6I (95\% Cl: 0.5I, 0.73); } \\
p<0.00 \text { I }\end{array}$ \\
\hline $\begin{array}{l}\text { CVD-REAL Nordic* } \\
(2017)^{26}\end{array}$ & $\begin{array}{l}\text { T2DM; new users of SGLT2 } \\
\text { inhibitors or other GLD }\end{array}$ & $\begin{array}{l}\text { (Not } \\
\text { randomized; } \\
\text { observational) } \\
91,320\end{array}$ & $\begin{array}{l}\text { Retrospective } \\
\text { registries study }\end{array}$ & $\begin{array}{l}\text { SGLT2 inhibitors } \\
\text { versus other classes } \\
\text { of GLD }\end{array}$ & $\begin{array}{l}\text { CV death; HR } 0.53 \text { ( } 95 \% \mathrm{Cl}: 0.40 \text {, } \\
0.7 \mathrm{I}) \text {; } p<0.000 \mathrm{I} \text {; Composite: } \\
\text { CV death, MI, or stroke; HR 0.78 } \\
\text { (95\% Cl: } 0.69,0.87) ; p<0.000 \mathrm{I} \text {; } \\
\text { Hospitalization for heart failure; } \\
\text { HR } 0.70 \text { ( } 95 \% \mathrm{Cl}: 0.6 \mathrm{I}, 0.8 \mathrm{I}) \text {; } \\
p<0.000 \mathrm{I}\end{array}$ \\
\hline
\end{tabular}

Notes: Bold text indicates superiority in reducing risk of major adverse CV events (MACE) demonstrated versus placebo. SAVOR-TIMI 53, Saxagliptin Assessment of Vascular Outcomes Recorded in Patients with Diabetes Mellitus-Thrombolysis in Myocardial Infarction; EXAMINE, Examination of Cardiovascular Outcomes with Alogliptin versus Standard of Care; TECOS, Trial Evaluating Cardiovascular Outcomes with Sitagliptin; ELIXA, Evaluation of LIXisenatide in Acute Coronary Syndrome; LEADER, Liraglutide Effect and Action in Diabetes: Evaluation of Cardiovascular Outcome Results; SUSTAIN-6, Trial to Evaluate Cardiovascular and Other Long-term Outcomes with Semaglutide in Subjects with Type 2 Diabetes; EXSCEL, Exenatide Study of Cardiovascular Event Lowering Trial; FREEDOM CVO, A Study to Evaluate Cardiovascular Outcomes in Patients With Type 2 Diabetes Treated With ITCA 650; DEVOTE, A Trial Comparing Cardiovascular Safety of Insulin Degludec Versus Insulin Glargine in Subjects With Type 2 Diabetes at High Risk of Cardiovascular Events; TOSCA.IT, Thiazolidinediones Or Sulphonylureas and Cardiovascular Accidents. Intervention Trial; EMPA-REG OUTCOME, Empagliflozin Removal of Excess Glucose: Cardiovascular OUTCOME Event Trial in Type 2 Diabetes Mellitus Patients; CANVAS Program, CANVAS, Canagliflozin Cardiovascular Assessment Study, + CANVAS-R, A Study of the Effects of Canagliflozin on Renal Endpoints in Adult Participants With Type 2 Diabetes Mellitus; CVD-REAL, Comparative Effectiveness of Cardiovascular Outcomes in New Users of Sodium-Glucose Cotransporter-2 Inhibitors (listed by alphabetical order of drug class and then by chronological order of primary publication). *CVD-REAL is included for completeness, as the data support the CV benefits of SGLT2 inhibitors in T2DM, as demonstrated in EMPA-REG OUTCOME and the CANVAS Program.

Abbreviations: Cl, confidence interval; CV, cardiovascular; CVD, cardiovascular disease; DPP-4, dipeptidyl peptidase-4; GLD, glucose-lowering drug; GLP-I, glucagon-like peptide- I; HbA I c, glycated hemoglobin; HR, hazard ratio; MI, myocardial infarction; PPAR, peroxisome proliferator-activated receptor; SGLT2, sodium glucose cotransporter 2; T2DM, type 2 diabetes mellitus; UA, unstable angina.

Saxagliptin Assessment of Vascular Outcomes Recorded in Patients with Diabetes Mellitus-Thrombolysis in Myocardial Infarction 53 (SAVOR-TIMI 53), ${ }^{13}$ Examination of Cardiovascular Outcomes with Alogliptin versus Standard of Care (EXAMINE), ${ }^{14}$ Trial Evaluating Cardiovascular Outcomes with Sitagliptin (TECOS), ${ }^{15}$ Evaluation of LIXisenatide in Acute Coronary Syndrome (ELIXA), ${ }^{16}$ and Exenatide Study of Cardiovascular Event Lowering Trial (EXSCEL); ${ }^{19}$ in addition, Thiazolidinediones Or Sulphonylureas and Cardiovascular Accidents. Intervention Trial (TOSCA.IT) demonstrated no significant differences between treatment groups in the prespecified CV outcomes. ${ }^{22}$ Evidence that a 
Table 2 Ongoing drug-specific CV outcome trials in patients with T2DM

\begin{tabular}{|c|c|c|c|c|c|}
\hline $\begin{array}{l}\text { Trial acronym } \\
\text { (ClinicalTrials.gov } \\
\text { identifier) }^{\mathrm{a}} \\
\end{array}$ & Patient population & $\begin{array}{l}\text { Estimated } \\
\text { enrollment, } \mathbf{N}^{\mathrm{b}}\end{array}$ & Intervention & Primary outcome & $\begin{array}{l}\text { Estimated } \\
\text { end date }\end{array}$ \\
\hline \multicolumn{6}{|l|}{ DPP-4 inhibitors } \\
\hline $\begin{array}{l}\text { CARMELINA } \\
\text { (NCT0I897532) }\end{array}$ & $\begin{array}{l}\text { HbAIc } 6.5 \%-10 \% \text {; } \geq 18 \text { years; } \\
\text { high CV risk defined by micro- or } \\
\text { macroalbuminuria and previous } \\
\text { macrovascular disease and/ } \\
\text { or impaired renal function with } \\
\text { predefined UACR }\end{array}$ & 7053 & $\begin{array}{l}\text { Linagliptin versus } \\
\text { placebo }\end{array}$ & $\begin{array}{l}\text { Composite: CV } \\
\text { death, non-fatal MI, } \\
\text { non-fatal stroke, or } \\
\text { hospitalization for UA }\end{array}$ & $\begin{array}{l}\text { December } \\
2017\end{array}$ \\
\hline $\begin{array}{l}\text { CAROLINA } \\
(\text { NCTOI } 243424)^{27}\end{array}$ & $\begin{array}{l}\text { HbAlc 6.5\%-8.5\% (SU naïve) or } \\
6.5 \%-7.5 \% \text { (previous SU exposure); } \\
40-85 \text { years; CV risk }\end{array}$ & 6072 & $\begin{array}{l}\text { Linagliptin versus } \\
\text { glimepiride }\end{array}$ & $\begin{array}{l}\text { Composite: CV } \\
\text { death, non-fatal MI, } \\
\text { non-fatal stroke, or } \\
\text { hospitalization for UA }\end{array}$ & March 2019 \\
\hline \multicolumn{6}{|l|}{$\begin{array}{l}\text { GLP-I receptor } \\
\text { agonists }\end{array}$} \\
\hline $\begin{array}{l}\text { REWIND } \\
\text { (NCTOI394952) }\end{array}$ & $\begin{array}{l}\mathrm{HbAlc} \leq 9.5 \% ; 50 \text { years }+\mathrm{CVD} ; 55 \\
\text { years + subclinical CVD; } \geq 60 \text { years } \\
+\mathrm{CV} \text { risk factors }\end{array}$ & 9622 & $\begin{array}{l}\text { Dulaglutide versus } \\
\text { placebo }\end{array}$ & $\begin{array}{l}\text { Composite: CV death, } \\
\text { non-fatal MI, or non- } \\
\text { fatal stroke }\end{array}$ & July 2018 \\
\hline $\begin{array}{l}\text { HARMONY } \\
\text { Outcomes } \\
\text { (NCT024655I5) }\end{array}$ & $\mathrm{HbAlc}>7.0 \% ; 40$ years + CVD & 9400 & $\begin{array}{l}\text { Albiglutide versus } \\
\text { placebo }\end{array}$ & $\begin{array}{l}\text { Composite: CV death, } \\
\text { MI, or stroke }\end{array}$ & May 2019 \\
\hline \multicolumn{6}{|l|}{ SGLT2 inhibitors } \\
\hline $\begin{array}{l}\text { DECLARE-TIMI } 58 \\
\text { (NCT0I730534) }\end{array}$ & $\begin{array}{l}\text { HbAlc criteria not stated; } \geq 40 \\
\text { years; known CVD or high CV risk }\end{array}$ & 17,276 & $\begin{array}{l}\text { Dapagliflozin } 10 \mathrm{mg} \\
\text { versus placebo }\end{array}$ & $\begin{array}{l}\text { Composite: CV death, } \\
\text { MI, or stroke } \\
\text { Composite: CV death } \\
\text { or hospitalization for } \\
\text { heart failure }\end{array}$ & April 2019 \\
\hline $\begin{array}{l}\text { CREDENCE } \\
(\text { NCT0206579I })^{28}\end{array}$ & $\begin{array}{l}\text { HbAlc } 6.5 \%-12.0 \% ; \geq 30 \text { years; } \\
\text { eGFR } \geq 30-<90 \mathrm{~mL} / \mathrm{min} / 1.73 \mathrm{~m}^{2} ; \\
\text { stable dose ACE inhibitor or ARB; } \\
\text { UACR }>300-\leq 5000 \mathrm{mg} / \mathrm{g}\end{array}$ & 4200 & $\begin{array}{l}\text { Canagliflozin } 100 \mathrm{mg} \\
\text { versus placebo }\end{array}$ & $\begin{array}{l}\text { Composite: end- } \\
\text { stage kidney disease, } \\
\text { doubling of serum } \\
\text { creatinine, renal or } \\
\text { CV death }\end{array}$ & June 2019 \\
\hline $\begin{array}{l}\text { VERTIS CV trial } \\
\text { (NCT0I98688I) }\end{array}$ & $\begin{array}{l}\mathrm{HbAlc} 7.0 \%-10.5 \% ; \geq 40 \\
\text { years; history or evidence of } \\
\text { atherosclerotic vascular disease }\end{array}$ & 8000 & $\begin{array}{l}\text { Ertugliflozin } 5 \mathrm{mg} \\
\text { versus ertugliflozin } \\
15 \mathrm{mg} \text { versus } \\
\text { placebo }\end{array}$ & $\begin{array}{l}\text { Composite: CV death, } \\
\text { non-fatal MI, or non- } \\
\text { fatal stroke }\end{array}$ & $\begin{array}{l}\text { October } \\
2019\end{array}$ \\
\hline
\end{tabular}

Notes: REWIND, Researching Cardiovascular Events With a Weekly Incretin in Diabetes (https://clinicaltrials.gov/ct2/show/NCT0I394952); HARMONY Outcomes, Effect of Albiglutide, When Added to Standard Blood Glucose Lowering Therapies, on Major Cardiovascular Events in Subjects With Type 2 Diabetes Mellitus (https://clinicaltrials. gov/ct2/show/record/NCT024655I5); CAROLINA, Cardiovascular Outcome Study of Linagliptin Versus Glimepiride in Patients With Type 2 Diabetes (https://clinicaltrials. gov/ct2/show/NCT0I243424); CARMELINA, Cardiovascular and Renal Microvascular Outcome Study With Linagliptin in Patients With Type 2 Diabetes Mellitus (https:// clinicaltrials.gov/ct2/show/NCT01897532); CREDENCE, Evaluation of the Effects of Canagliflozin on Renal and Cardiovascular Outcomes in Participants With Diabetic Nephropathy (https://clinicaltrials.gov/ct2/show/NCT0206579I); DECLARE-TIMI 58, Dapagliflozin Effects on Cardiovascular Events - Thrombolysis in Myocardial Infarction (https://clinicaltrials.gov/ct2/show/NCTOI730534); VERTIS CV, Cardiovascular Outcomes Following Ertugliflozin Treatment in Type 2 Diabetes Mellitus Participants With Vascular Disease (https://clinicaltrials.gov/ct2/show/NCT0I98688I) (listed by alphabetical order of drug class and then by chronological order of estimated study end date). ${ }^{a}$ Citation listed if study details were published. ${ }^{b}$ Data per ClinicalTrials.gov.

Abbreviations: ACE, angiotensin-converting enzyme; ARB, angiotensin receptor blocker; CV, cardiovascular; CVD, cardiovascular disease; DPP-4, dipeptidyl peptidase-4; eGFR, estimated glomerular filtration rate; GLP-I, glucagon-like peptide-I; HbAIc, glycated hemoglobin; MI, myocardial infarction; SGLT2, sodium glucose cotransporter 2; $\mathrm{SU}$, sulfonylurea; T2DM, type 2 diabetes mellitus; UA, unstable angina; UACR, urine albumin to creatinine ratio.

glucose-lowering agent could lower the risk of CV events, ie, show superiority in reducing the risk of MACE in diabetes patients with high CV risk, has been demonstrated in four CVOTs in T2DM to date (see also Table 3). ${ }^{17,18,23,24,29,30}$ The first of these was EMPAgliflozin Removal of Excess Glucose: Cardiovascular OUTCOME Event Trial in Type 2 Diabetes Mellitus Patients (EMPA-REG OUTCOME ${ }^{\circledR}$ ), which investigated the sodium glucose cotransporter 2 (SGLT2) inhibitor empagliflozin. ${ }^{23}$ This was followed by CVOTs of the glucagon-like peptide-1 receptor agonists, liraglutide (Liraglutide Effect and Action in Diabetes: Evaluation of Cardiovascular Outcome Results [LEADER]) $)^{17}$ and semaglutide (Trial to Evaluate Cardiovascular and Other Longterm Outcomes with Semaglutide in Subjects with Type 2 Diabetes [SUSTAIN-6]). ${ }^{18}$ Most recently, CVOT data from another SGLT2 inhibitor, canagliflozin, have been published 
Table 3 Summary of results from CV outcome trials of glucose-lowering drugs in patients with T2DM showing reduction in risk of $\mathrm{CV}$ events versus placebo

\begin{tabular}{|c|c|c|c|c|}
\hline Trial name & Drug & Effect on risk of CV outcome & & CV indications per US prescribing information \\
\hline \multirow[t]{6}{*}{ EMPA-REG OUTCOME ${ }^{23}$} & Empagliflozin & MACE & $\downarrow$ & To reduce the risk of $\mathrm{CV}$ death in adult patients with T2DM \\
\hline & & All-cause mortality ${ }^{\mathrm{a}}$ & $\downarrow$ & and established CV disease \\
\hline & & $\mathrm{CV}$ mortality & $\downarrow$ & \\
\hline & & Non-fatal MI & NSD & \\
\hline & & Non-fatal stroke & NSD & \\
\hline & & Hospitalization for heart failure ${ }^{a}$ & $\downarrow$ & \\
\hline \multirow[t]{6}{*}{ LEADER $^{17}$} & Liraglutide & MACE & $\downarrow$ & To reduce the risk of MACE (CV death, non-fatal MI, or non- \\
\hline & & All-cause mortality ${ }^{\mathrm{a}}$ & $\downarrow$ & fatal stroke) in adults with T2DM and established CV disease ${ }^{c}$ \\
\hline & & CV mortality & $\downarrow$ & \\
\hline & & Non-fatal MI & NSD & \\
\hline & & Non-fatal stroke & NSD & \\
\hline & & Hospitalization for heart failure ${ }^{a}$ & NSD & \\
\hline \multirow[t]{6}{*}{ SUSTAIN-618 } & Semaglutide & MACE & $\downarrow$ & Not FDA approved to date; FDA regulatory submission in \\
\hline & & All-cause mortality ${ }^{a}$ & NSD & progress \\
\hline & & CV mortality & NSD & \\
\hline & & Non-fatal MI & NSD & \\
\hline & & Non-fatal stroke & $\downarrow$ & \\
\hline & & Hospitalization for heart failure ${ }^{a}$ & NSD & \\
\hline \multirow[t]{6}{*}{ CANVAS Program ${ }^{24}$} & Canagliflozin & MACE & $\downarrow$ & No FDA-approved CV indications to date; supplemental New \\
\hline & & All-cause mortality & b & Drug Application submitted to FDA for new indication to \\
\hline & & CV mortality & b & reduce risk of MACE, October 2017 \\
\hline & & Non-fatal MI & b & \\
\hline & & Non-fatal stroke & b & \\
\hline & & Hospitalization for heart failure ${ }^{\mathrm{a}}$ & b & \\
\hline
\end{tabular}

Notes: EMPA-REG OUTCOME, Empagliflozin Removal of Excess Glucose: Cardiovascular OUTCOME Event Trial in Type 2 Diabetes Mellitus Patients; LEADER, Liraglutide Effect and Action in Diabetes: Evaluation of Cardiovascular Outcome Results; SUSTAIN-6, Trial to Evaluate Cardiovascular and Other Long-term Outcomes with Semaglutide in Subjects with Type 2 Diabetes; CANVAS Program, CANVAS, Canagliflozin Cardiovascular Assessment Study, + CANVAS-R, A Study of the Effects of Canagliflozin on Renal Endpoints in Adult Participants With Type 2 Diabetes Mellitus (listed in chronological order of primary publication). ${ }^{a}$ Not part of MACE outcome. ${ }^{b} \mathrm{Hypothesis} \mathrm{testing}$ was discontinued, as superiority versus placebo was not shown for all-cause mortality (which was the first secondary outcome in the testing sequence). ${ }^{24}$ 'The FDA decision was based on results from the LEADER trial, which demonstrated that liraglutide reduced the risk of MACE by $13 \%$ versus placebo ( $p=0.0 \mathrm{I}$ for superiority), ${ }^{29}$ with an absolute risk reduction of $1.9 \%$; this was driven by a significant reduction in $\mathrm{CV}$ death (absolute risk reduction of I.3\%), with numerical (but not statistically significant) favorable differences in non-fatal MI and non-fatal stroke. ${ }^{30}$

Abbreviations: $\downarrow$, statistically significant decrease; CV, cardiovascular; FDA, US Food and Drug Administration; MACE, major adverse cardiovascular event; MI, myocardial infarction; NSD, no statistically significant difference; T2DM, type 2 diabetes mellitus.

in the CANagliflozin CardioVascular Assessment Study (CANVAS Program) report, and these data support the CV benefits in T2DM patients observed with this drug class. ${ }^{24}$ A further report of "real-world" data for CV outcomes in T2DM patients receiving SGLT2 inhibitors was published recently, when Comparative Effectiveness of Cardiovascular Outcomes in New Users of Sodium-Glucose Cotransporter-2 Inhibitors (CVD-REAL) demonstrated that SGLT2 inhibitors reduced the risk of hospitalization for heart failure when compared with other classes of glucose-lowering drugs. ${ }^{25,26}$ It should be noted that the CVD-REAL study differs from the aforementioned trials in that it was a non-randomized registry study, rather than a dedicated CVOT; nonetheless, it is included herein for completeness, as it provides additional CV outcomes data for US-approved SGLT2 inhibitors.

This report discusses the results of EMPA-REG OUTCOME, the CANVAS Program, and CVD-REAL, and - with a focus on EMPA-REG OUTCOME - examines the possible mechanisms by which SGLT2 inhibitors may reduce $\mathrm{CV}$ risk in patients with T2DM.

\section{Summary of results from EMPA-REG OUTCOME}

EMPA-REG OUTCOME was the first CVOT of an SGLT2 inhibitor to publish final data. ${ }^{23}$ Briefly, this was a multicenter, randomized, double-blind, placebo-controlled trial to assess the effect on CV events of once-daily empagliflozin (10 mg or $25 \mathrm{mg}$ ) versus placebo administered in addition to standard care in adults with T2DM and established CVD. ${ }^{23}$ A total of 7020 patients with T2DM were randomized, and major inclusion criteria included established CVD (defined as previous myocardial infarction [MI], coronary artery disease, unstable angina, stroke, or occlusive peripheral arterial disease), body mass index of $45 \mathrm{~kg} / \mathrm{m}^{2}$ or less, and estimated glomerular filtration rate (eGFR) of at least $30 \mathrm{~mL} / \mathrm{min} / 1.73 \mathrm{~m}^{2}$. The mean age of the patients was 63 years, $28 \%$ were female, 
$57 \%$ had been diagnosed with T2DM for at least 10 years, and 99\% had established CVD. The patient population was well treated for CV risk factors; at baseline, $\sim 81 \%$ of patients were receiving angiotensin-converting enzyme (ACE) inhibitors and/or angiotensin receptor blockers (ARBs), $\sim 65 \%$ were receiving beta-blockers, and $\sim 3 \%$ were receiving diuretics. ${ }^{23}$ The primary outcome was a composite, known as 3-point MACE, consisting of death from CV causes, non-fatal MI, or non-fatal stroke, as analyzed in the pooled empagliflozin group versus the placebo group. The key secondary outcome was a composite of the primary outcome plus hospitalization for unstable angina. The median duration of treatment was 2.6 years, and the median observation time was 3.1 years. ${ }^{23}$ Results demonstrated that the primary outcome occurred in significantly fewer patients in the empagliflozin group versus the placebo group ( $10.5 \%$ vs $12.1 \%$, respectively; hazard ratio [HR] 0.86; 95.02\% confidence interval [CI] 0.74-0.99; $p=0.04$ for superiority) (Table 4$),{ }^{23}$ equating to a $14 \%$ relative risk reduction (RRR) in 3-point MACE. When the MACE components were analyzed separately, there was a $38 \%$ RRR in CV death with empagliflozin compared with placebo, a $35 \%$ RRR for hospitalization for heart failure, and a $32 \%$ RRR in all-cause mortality, all of which were statistically significant. ${ }^{23}$ However, there was no significant difference in the rates of non-fatal MI or non-fatal stroke. ${ }^{23}$ In analyses of subgroups according to baseline characteristics, there was some heterogeneity for the primary outcome, but reductions in the risk of $\mathrm{CV}$ death were consistent across subgroups. ${ }^{23}$ In terms of safety, participants receiving empagliflozin had an increased rate of genital infection ( $6.4 \%$ vs $1.8 \%$ for placebo) and urosepsis $(0.4 \%$ vs $0.1 \%$ for placebo), but there were no between-group differences in other adverse events (including confirmed hypoglycemic events, acute renal failure, diabetic ketoacidosis, thromboembolic events, bone fracture, volume depletion events, complicated urinary tract infection, or pyelonephritis). ${ }^{23}$

Differences in the primary endpoint between empagliflozin and placebo during EMPA-REG OUTCOME were driven by the significant reduction in $\mathrm{CV}$ death. ${ }^{23}$ The reduction in the risk of CV death occurred early in the study (the event curve for empagliflozin separated from placebo within 12 weeks of starting study drug treatment) and continued throughout the study period. ${ }^{23}$ A similar observation was made for the risk reduction in all-cause mortality. ${ }^{23}$ This is earlier than might be predicted for glucose-lowering effects, based on the observed between-group differences in $\mathrm{HbA} 1 \mathrm{c}$ values $\left(0.45 \%\right.$ at 90 weeks and $0.28 \%$ at 204 weeks) ${ }^{31}$ The early reduction in $\mathrm{CV}$ death, occurring without significant reductions in non-fatal $\mathrm{MI}$ or non-fatal stroke, suggests that empagliflozin could improve $\mathrm{CV}$ survival rather than slow atherosclerosis and/or prevent atherosclerotic events. ${ }^{31}$ This early separation of event curves corresponds with results

Table 4 EMPA-REG OUTCOME: primary and selected secondary CV outcomes ${ }^{23}$

\begin{tabular}{|c|c|c|c|c|}
\hline Outcome & $\begin{array}{l}\text { Empagliflozin } \\
\text { pooled }(N=4687) \\
n(\%)\end{array}$ & $\begin{array}{l}\text { Placebo } \\
(N=2333) \\
n(\%)\end{array}$ & $\begin{array}{l}\text { Hazard ratio } \\
(95 \% \mathrm{Cl})\end{array}$ & $p$-value ${ }^{a}$ \\
\hline \multicolumn{5}{|l|}{$\begin{array}{l}\text { Median treatment and observation time, years } \\
\text { (interquartile range) }\end{array}$} \\
\hline Treatment & $2.6(2.0-3.4)$ & $2.6(1.8-3.4)$ & & \\
\hline Observation & $3.2(2.2-3.6)$ & $3.1(2.2-3.5)$ & & \\
\hline \multicolumn{5}{|l|}{ Primary outcome } \\
\hline Death from CV causes, non-fatal MI, or non-fatal stroke & $490(10.5)$ & $282(12.1)$ & $0.86(0.74,0.99)^{b}$ & $\begin{array}{l}\text { Non-inferiority }<0.001 \\
\text { Superiority } 0.04\end{array}$ \\
\hline \multicolumn{5}{|l|}{ Key secondary outcomes } \\
\hline $\begin{array}{l}\text { Death from CV causes, non-fatal MI, non-fatal stroke, } \\
\text { or hospitalization for UA }\end{array}$ & $599(12.8)$ & $333(14.3)$ & $0.89(0.78,1.01)$ & $\begin{array}{l}\text { Non-inferiority }<0.001 \\
\text { Superiority } 0.08\end{array}$ \\
\hline Death from any cause & $269(5.7)$ & $194(8.3)$ & $0.68(0.57,0.82)$ & $<0.001$ \\
\hline Death from CV causes & $172(3.7)$ & $137(5.9)$ & $0.62(0.49,0.77)$ & $<0.001$ \\
\hline Fatal or non-fatal MI excluding silent $\mathrm{MI}$ & $223(4.8)$ & $126(5.4)$ & $0.87(0.70,1.09)$ & 0.23 \\
\hline Non-fatal MI excluding silent MI & $213(4.5)$ & $|2|(5.2)$ & $0.87(0.70,1.09)$ & 0.22 \\
\hline Hospitalization for UA & $133(2.8)$ & $66(2.8)$ & $0.99(0.74,1.34)$ & 0.97 \\
\hline Fatal or non-fatal stroke & $164(3.5)$ & $69(3.0)$ & $1.18(0.89,1.56)$ & 0.26 \\
\hline Non-fatal stroke & $150(3.2)$ & $60(2.6)$ & $1.24(0.92,1.67)$ & 0.16 \\
\hline Hospitalization for heart failure & $126(2.7)$ & $95(4.1)$ & $0.65(0.50,0.85)$ & 0.002 \\
\hline
\end{tabular}

Notes: ${ }^{a}$ One-sided $p$-values are shown for tests of non-inferiority; two-sided $p$-values are shown for tests of superiority. ${ }^{\mathrm{b}} 95.02 \% \mathrm{Cl}$.

Abbreviations: $\mathrm{Cl}$, confidence interval; CV, cardiovascular; EMPA-REG OUTCOME, Empagliflozin Removal of Excess Glucose: Cardiovascular OUTCOME Event Trial in Type 2 Diabetes Mellitus Patients; MI, myocardial infarction; UA, unstable angina. 
observed with aldosterone antagonists in heart failure studies such as EPlerenone Post-Acute Myocardial Infarction Heart Failure Efficacy and SUrvival Study (EPHESUS). ${ }^{32}$ Conversely, changes in CV outcomes with liraglutide versus placebo in the LEADER trial were not observed until approximately 12 months of follow-up. ${ }^{17}$

The reduction in hospitalization for heart failure with empagliflozin was an unexpected result during EMPA-REG OUTCOME, and may suggest that this agent could affect ventricular function in addition to its diuretic effects. Subsequent data analysis showed a consistent benefit of empagliflozin therapy in those with and without heart failure at baseline. ${ }^{33}$ However, it is important to note that the diagnosis of heart failure at baseline in EMPA-REG OUTCOME was based on investigators' clinical assessment without measuring biomarkers or ejection fraction ( $\sim 10 \%$ of patients were diagnosed with heart failure at baseline); accordingly, it is possible that a further proportion of patients in the study may have had mild or subclinical heart failure, silent ischemia, or undiagnosed diabetic cardiomyopathy. ${ }^{34}$ As with the observed reduction in $\mathrm{CV}$ death, the effect of empagliflozin on heart failure hospitalization occurred very early in the trial. Again, this is suggestive of a non-atherosclerotic driven effect. ${ }^{33}$ Potential contributory factors include reduced cardiac preload and afterload, reduced plasma volume, osmotic diuresis, reduced arterial stiffness, and decreased double product or rate pressure product (heart rate multiplied by systolic blood pressure [BP]), as well as reductions in body weight, BP, and hyperglycemia. ${ }^{33}$ Other mechanisms may also have a role, although supporting data are limited at present. For example, increased activity of the sodium/hydrogen exchanger (NHE) is associated with heart failure; empagliflozin was shown recently to directly inhibit the NHE in isolated animal ventricular myocytes, independent of SGLT2 activity. ${ }^{35}$ Furthermore, in a small study $(\mathrm{N}=10)$ of patients with T2DM and established CVD, short-term empagliflozin treatment was associated with a significant reduction in left ventricular mass index and improved diastolic function. ${ }^{36}$ Additional studies are needed to expand on these sets of preliminary data.

\section{Summary of results from CANVAS Program}

The CANVAS Program was an integrated analysis of data from two CVOTs, CANVAS and CANVAS-Renal Endpoints (CANVAS-R), and involved 10,142 patients with T2DM and high CVD risk or established CVD who were randomized to receive canagliflozin $(100 \mathrm{mg}, 300 \mathrm{mg}$, or
100-300 mg up-titrated, daily) versus placebo. ${ }^{24}$ Patients had a mean age of 63 years, $36 \%$ were female, mean duration of diabetes was 13.5 years, and $66 \%$ had a history of CVD at baseline. Approximately $80 \%$ of patients were prescribed renin-angiotensin-aldosterone system (RAAS) inhibitors at baseline, $53 \%$ were prescribed beta-blockers, and $44 \%$ were prescribed diuretics. The primary outcome was 3-point MACE. Sequential conditional hypothesis testing was planned for the secondary outcomes of all-cause death, $\mathrm{CV}$ death, progression of albuminuria, and the composite of $\mathrm{CV}$ death and hospitalization for heart failure; however, if sequential testing was not significant for all of these outcomes, the remaining outcomes were scheduled for assessment as exploratory variables in the integrated dataset. ${ }^{24}$ Mean follow-up was 290-298 weeks for CANVAS and 108 weeks for CANVAS-R; overall mean follow-up was 188 weeks (median $\sim 126$ weeks). There was a $14 \%$ reduction in the risk of $\mathrm{CV}$ events for canagliflozin versus placebo (3-point MACE, 26.9 vs 31.5 participants per 1000 patient-years; HR 0.86 ; 95\% CI: $0.75-0.97 ; p=0.02$ for superiority); however, the effects of the individual MACE components did not reach statistical significance. CANVAS Program data also showed that patients treated with canagliflozin had a lower risk of hospitalization for heart failure versus placebo; however, this was tested in an exploratory manner. Although the primary endpoint result of the CANVAS Program was similar to that reported in EMPA-REG OUTCOME, there were some noteworthy differences between the efficacy results of these trials; specifically, the significant reductions in $\mathrm{CV}$ death and all-cause death demonstrated with empagliflozin were not shown with canagliflozin. Commentators suggested that this may be due to the fact that only two-thirds of the patients in the CANVAS Program had established CVD (vs all patients in EMPA-REG OUTCOME) $\cdot{ }^{37}$ Canagliflozin treatment was associated with adverse events previously reported with SGLT2 inhibitors, such as genital infection, volume depletion, and diuresis; however, there was no increased risk in other adverse events versus placebo (including hypoglycemic events, hyperkalemia, acute kidney injury, pancreatitis, malignancies, diabetic ketoacidosis, or venous thromboembolism). ${ }^{24} \mathrm{An}$ increased risk of amputation was reported for canagliflozin versus placebo (6.3 vs 3.4 participants per 1000 patient-years, respectively; HR 1.97; 95\% CI: 1.41, 2.75), primarily occurring at the level of the toe or metatarsal; and there was a higher rate of bone fracture (15.4 vs 11.9 participants with fracture per 1000 patient-years, respectively; HR 1.26; $95 \%$ CI: $1.04,1.52) .^{24}$ 


\section{Summary of results from CVD-REAL}

Data from the first large, real-world study of patients with T2DM, both with and without established CVD, were recently published in the CVD-REAL study, which compared $\mathrm{CV}$ outcomes in patients newly receiving SGLT2 inhibitors versus other classes of glucose-lowering drugs. ${ }^{25,26}$ The aims of the study - a retrospective observational cohort analysis - were to determine if the findings of EMPA-REG OUTCOME could be applied to real-world clinical practice, and to investigate whether similar benefits could be expected in T2DM patients with a broader CV risk profile. ${ }^{25}$ Following propensity score matching, 154,528 patients who were new users of an SGLT2 inhibitor were selected from patient registry datasets from six countries (US, Germany, Sweden, Norway, Denmark, and UK) and matched (1:1) with patients who were new users of other glucose-lowering drugs. ${ }^{25}$ Patients had a mean age of 57 years, $44 \%$ were female, and $13 \%$ had established CVD. At baseline, approximately $80 \%$ of all patients received BP-lowering therapy (of which $75 \%$ received ACE inhibitors or ARBs), $67 \%$ received statins, and $79 \%$ received metformin. The primary outcome was the risk of hospitalization for heart failure (inpatient or outpatient visit); secondary outcomes included all-cause mortality and a composite endpoint of hospitalization for heart failure or all-cause mortality. Safety was not examined. Mean duration of follow-up for hospitalization for heart failure was 239 days in the SGLT2 inhibitor group and 211 days in the other glucose-lowering drugs group. Treatment with an SGLT2 inhibitor versus other glucose-lowering drugs was associated with a 39\% RRR in hospitalization for heart failure, a $51 \%$ RRR in all-cause mortality, and a $46 \%$ RRR in the composite endpoint. ${ }^{25}$ As $87 \%$ of patients did not have established CVD, the investigators concluded that these data suggest possible $\mathrm{CV}$ benefits for a broad population of patients with T2DM. ${ }^{25}$ (However, this would contradict the suggested explanation for observed differences between EMPA-REG OUTCOME and the CANVAS Program as being related to the different proportion of patients with established CVD in each study.) Also, as there was a lack of significant heterogeneity in the data across the six countries, despite geographic variations in individual SGLT2 inhibitor use (United States: canagliflozin $\sim 76 \%$, dapagliflozin $\sim 19 \%$, empagliflozin $\sim 5 \%$; European countries combined: canagliflozin $\sim 2 \%$, dapagliflozin $\sim 92 \%$, empagliflozin $\sim 6 \%$ ), these data appear to be related to the SGLT2 inhibitor drug class rather than to an individual SGLT2 inhibitor agent. ${ }^{25}$
The CVD-REAL Nordic sub-study (carried out in Sweden, Norway, and Denmark) also published CV morbidity and mortality data recently. ${ }^{26} \mathrm{The} \mathrm{CV}$ outcomes investigated were CV mortality, 3-point MACE, hospitalization for heart failure (inpatient or outpatient visit), non-fatal MI, non-fatal stroke, and atrial fibrillation. After propensity score matching (1:3), 91,320 patients were included in either the new users of SGLT2 inhibitors group $(n=22,830)$ or the new users of other glucose-lowering drugs group $(n=68,490)$. Patients had a mean age of 61 years, $40 \%$ were female, time since first glucose-lowering drug treatment was 7-8 years, baseline prevalence of CVD and microvascular comorbidity was $25 \%$ for each, and the prevalence of baseline medications was similar to that described in the CVD-REAL study. Mean follow-up was 0.9 years. Dapagliflozin use accounted for $94 \%$ of the total SGLT2 inhibitor exposure, with 5\% for empagliflozin and $1 \%$ for canagliflozin. ${ }^{26}$ Compared with other classes of glucose-lowering drugs, treatment with an SGLT2 inhibitor was associated with a 47\% RRR in CV mortality, 22\% RRR in MACE, and 30\% RRR in hospitalization for heart failure. ${ }^{26}$

Although the data from CVD-REAL are supportive for SGLT2 inhibitor-associated CV benefits, it must be noted that real-world observational studies do not provide the same level of evidence as randomized controlled trials, due to factors such as bias (eg, immortal time bias, channeling, differences in patient selection, treatment adherence, assessment of outcomes, and/or withdrawals from the study ${ }^{38}$ ), incomplete or inaccurate data, and/or lack of standardization of outcomes measures across all study sites..$^{38}$ In addition, biases in the real-world setting may be overlooked because of the large number of participants in such studies. Several other limitations and observations of the CVD-REAL study have been discussed, ${ }^{39}$ including the fact that although $>90 \%$ of SGLT2 inhibitor group patients in CVD-REAL Nordic were exposed to dapagliflozin, CV safety and any $\mathrm{CV}$ benefits of this agent will only be established following the final results of the DECLARE-TIMI 58 CVOT, which are due in $2019 .{ }^{39}$

\section{Effect of SGLT2 inhibitors on CV risk factors}

The available literature on the associated beneficial effects of empagliflozin on $\mathrm{CV}$ risk factors is larger than that for the other SGLT2 inhibitors; therefore, the following discussion relates primarily to empagliflozin and EMPA-REG OUTCOME. 
Understanding how SGLT2 inhibitors affect various $\mathrm{CV}$ risk factors may provide an explanation of the possible mechanisms responsible for the $\mathrm{CV}$ benefits observed with SGLT2 inhibitors. SGLT2 inhibitors are the most recent class of glucose-lowering agents to gain regulatory approval for use in the treatment of patients with T2DM, and their mechanism of action is well documented. ${ }^{40}$ Briefly, SGLT2 inhibitors reduce renal glucose reabsorption and increase urinary glucose excretion, thereby lowering elevated blood glucose levels..$^{40}$ SGLT2, a sodium glucose cotransporter protein, is responsible for the majority ( $97 \%)$ of glucose reabsorption in the kidney and is located in the early proximal tubule; its family member SGLT1 has a minor role in renal glucose reabsorption. ${ }^{40}$ Studies using diabetic rodent models reported increased renal SGLT2 expression, ${ }^{41,42}$ resulting in elevated glucose reabsorption and preservation of hyperglycemia. ${ }^{40}$ Pharmacologic inhibition of renal SGLT2 reduces the capacity for renal glucose reabsorption by approximately $50 \%$, thus reducing the degree of hyperglycemia. ${ }^{40}$ The associated calorie loss contributes to reduced body weight, which together with modest diuresis and natriuresis lowers $\mathrm{BP}^{40}$ In addition to empagliflozin, three other SGLT2 inhibitors - canagliflozin, dapagliflozin, and ertugliflozin - were approved by the FDA..$^{40,43}$ Empagliflozin, canagliflozin, and dapagliflozin have marketing approval in the European Union as well as in other parts of the world. One additional SGLT2 inhibitor - sotagliflozin (a dual SGLT1/SGLT2 inhibitor) - is in advanced stages of clinical development in the US and Europe; and three further agents - ipragliflozin, tofogliflozin, and luseogliflozin - have been approved in Japan. ${ }^{40}$ Data from clinical trials of canagliflozin, dapagliflozin, and empagliflozin have established that these agents, given as monotherapy or in combination with other glucose-lowering agents, improve blood glucose control and are also associated with modest reductions in body weight and $\mathrm{BP}^{44}$ These and other effects reported during clinical trials of SGLT2 inhibitors are discussed in following sections with regard to possible explanations for the benefits to CV risk observed during EMPA-REG OUTCOME, which do not currently appear to be strongly related to effects on atherosclerosis.

\section{Glucose control}

SGLT2 inhibitors were designed to reduce hyperglycemia in T2DM, as demonstrated by a meta-analysis of 34 randomized controlled trials (duration $\geq 12$ weeks) of SGLT2 inhibitors that reported a mean decrease in $\mathrm{HbA} 1 \mathrm{c}$ of $0.69 \%$ and in fasting plasma glucose of $0.9 \mathrm{mmol} / \mathrm{L}(16.2 \mathrm{mg} / \mathrm{dL})$ versus placebo. ${ }^{44}$ However, the observed placebo-subtracted decrease in HbAlc during EMPA-REG OUTCOME was modest $(\sim 0.3 \%-0.4 \%)$ and comparable to that recorded in other CVOTs that reported neutral effects on CV outcomes (such as SAVOR-TIMI 53, EXAMINE, TECOS, and ELIXA) ${ }^{45}$ It should be noted that EMPA-REG OUTCOME was designed to have equivalent glucose control across treatment arms, allowing evaluation of CV safety to be independent of this factor. Thus, the early beneficial effects of empagliflozin on $\mathrm{CV}$ events observed in EMPA-REG OUTCOME are unlikely to be due to improvements in glucose lowering.

\section{Body weight and adiposity}

SGLT2 inhibitor-induced urinary glucose excretion is associated with an expected daily calorie loss of $\sim 240-320$ kilocalories (based on a daily urinary glucose excretion of $\sim 60-80 \mathrm{~g}^{46}$ ). Longer term ( $\geq 1$ year) clinical trials of SGLT2 inhibitors have shown that the caloric loss contributed by urinary glucose excretion is associated with modest decreases in body weight, mainly due to reduced body fat content (visceral and subcutaneous). ${ }^{47-49}$ Metabolic effects associated with SGLT2 inhibitors - including increased lipolysis, fat oxidation, and ketogenesis, plus decreased insulin secretion and increased glucagon release - also contribute to loss of fat and body weight. ${ }^{50}$ The reduction in the visceral adiposity associated with SGLT2 inhibitors is of interest as the abnormal adipocyte biology and altered production of adipokines associated with obesity have a role in increasing the metabolic risk for T2DM, $\mathrm{CV}$ complications, and overall mortality. ${ }^{51,52}$

\section{Energy metabolism and substrate utilization}

SGLT2 inhibitors cause a shift in the substrate for energy metabolism from carbohydrate to lipid utilization, and are also associated with decreased insulin secretion and increased glucagon release (ie, insulin-to-glucagon ratio decreases), thus promoting metabolic conditions for increased ketone production. ${ }^{50,53}$ In studies using rat models, ketones were shown to be a more efficient fuel source than fatty acids or glucose for the heart, ${ }^{54}$ and increased ketone levels were associated with increased cardiac efficiency at the mitochondrial level. ${ }^{55}$ In a diabetic rat model, SGLT2 inhibitors did not decrease blood levels of total ketones (ie, acetoacetate and beta-hydroxybutyrate) ${ }^{56}$ Therefore, it is conceivable that changes in metabolic substrate utilization associated with SGLT2 inhibitors could confer benefits to cardiac function, particularly in a failing heart, and contribute to the cardioprotective effects observed in EMPA-REG OUTCOME..$^{57,58}$ 


\section{Lipid profiles}

SGLT2 inhibitor clinical trials have reported small increases in the concentration of both low-density lipoprotein cholesterol (LDL-C) and high-density lipoprotein cholesterol (HDL-C), ${ }^{44}$ and these changes were also observed during EMPA-REG OUTCOME ${ }^{23}$ However, no significant changes in the LDL-C/HDL-C ratio were observed. ${ }^{59,60}$ Hemoconcentration associated with SGLT2 inhibitor treatment has been suggested as a possible mechanism to explain the increases in LDL-C and HDL-C. ${ }^{61}$ Recent pre-clinical data revealed that empagliflozin elevated LDL-C levels in fasting conditions via reduced LDL-C catabolism; the proposed explanation for this was a "starvation shift" in energy metabolism (caused by calorie loss from SGLT2 inhibition-associated urinary glucose excretion) from carbohydrate to lipid utilization that moderately increased ketone production and hepatic cholesterol synthesis, and resulted in increased LDL-C levels. ${ }^{62}$ However, the clinical relevance of these changes in LDL-C and HDL-C regarding CV outcomes is unclear at present, given that increased LDL-C is a risk factor for coronary heart disease.

\section{Uric acid}

SGLT2 inhibitors are associated with small reductions in serum uric acid levels, as observed during EMPA-REG OUTCOME. ${ }^{23}$ Higher serum uric acid levels are associated with CVD risk factors such as hypertension and obesity, and also with an increased risk of incident coronary heart disease, heart failure, and atrial fibrillation; however, it is unclear whether uric acid is a risk factor and/or a causative agent. ${ }^{63}$ The mechanism by which SGLT2 inhibitors decrease uric acid concentration is unknown, but may involve a direct effect on the kidneys via the uric acid transport system or an indirect effect arising from reduced sodium reabsorption in the proximal tubule..$^{64,65}$

\section{Blood pressure}

Clinical trials of SGLT2 inhibitors have reported modest reductions in systolic BP $(3-5 \mathrm{~mm} \mathrm{Hg})$ and diastolic BP (2-3 mm Hg) without compensatory tachycardia. ${ }^{66}$ This was confirmed in studies of SGLT2 inhibitors in patients with T2DM and hypertension that assessed BP via 24-hour ambulatory monitoring, in which significant reductions in mean systolic and diastolic BP occurred by week 12.67-69 In EMPA-REG OUTCOME, a decrease in systolic and diastolic BP of approximately 5 and $2 \mathrm{~mm} \mathrm{Hg}$, respectively, was observed. ${ }^{23,31}$ Nevertheless, reduced rates of $\mathrm{CV}$ events have been reported with even small BP reductions. ${ }^{70,71}$ The mechanistic basis for the observed BP reduction with SGLT2 inhibitors is not fully understood, ${ }^{66}$ but proposed mechanisms include diuretic effects, ${ }^{72,73}$ reduction in weight, ${ }^{74}$ and decreased arterial stiffness. ${ }^{75}$ Lowering BP by one or a combination of these mechanisms would be expected to provide prompt reduction of cardiac afterload and cardiac workload, decrease myocardial oxygen consumption, and reduce the power required to propel the stroke volume, which would have a rapid and beneficial effect on a patient with heart failure. This would be consistent with the reduction in heart failure hospitalization risk and with the early event curve separation observed in EMPA-REG OUTCOME. Having said that, a recently published post hoc mediation analysis of the EMPA-REG OUTCOME trial revealed that BP made a negligible contribution to the risk reduction of $\mathrm{CV}$ death with empagliflozin versus placebo $;{ }^{76}$ thus raising more questions on the probable multifaceted nature of empagliflozin's effects on CV outcomes.

\section{Effects on diuresis and RAAS}

The diuretic effect of SGLT2 inhibitors has been examined ${ }^{72,73}$ and considered a possible mechanism during EMPA-REG OUTCOME, ${ }^{77}$ as SGLT2 inhibitors exhibit some similarities with loop diuretics. ${ }^{73,78}$ SGLT2 inhibitors cause a prolonged reduction in extracellular fluid and plasma volume, ${ }^{72}$ which reduces cardiac preload and - as with reduced afterload results in lower cardiac work and oxygen consumption. In addition, the depletion of sodium by SGLT2 inhibitorassociated natriuresis, albeit short-lived, may have a beneficial role in patients with T2DM and heart failure. ${ }^{78}$

\section{Hematocrit}

Increased hematocrit was reported during EMPA-REG OUTCOME, ${ }^{23}$ and has been observed during other trials of SGLT2 inhibitor treatment. ${ }^{79}$ Hemoconcentration following SGLT2 inhibitor-related diuresis is assumed to contribute to the elevated hematocrit. Hematopoiesis may also have a role, ${ }^{79,80}$ as small increases in reticulocytes, red cell mass, and erythropoietin have been reported during SGLT2 inhibitor treatment. $^{72}$ The recent EMPA-REG OUTCOME trial post hoc mediation analysis already mentioned reported that changes in hematocrit and hemoglobin (ie, volume-related factors) appeared to be important mediators of CV mortality risk reduction. ${ }^{76}$

\section{Effects on RAAS}

The activity of RAAS during clinical studies of SGLT2 inhibitors was found to be slightly increased but within 
normal parameters, ${ }^{66,72,81}$ indicating a possible compensatory response to the resulting reductions in intravascular volume and BP. ${ }^{66}$ It has been suggested, however, that empagliflozin may act via non-classic RAAS pathways and that this may explain the decreased risk of CV events during EMPA-REG OUTCOME. ${ }^{82}$ It is hypothesized that instead of acting via the type 1 angiotensin II (T1-AT2) receptor, which contributes to the pathogenesis of CVD, empagliflozin may increase activation of the type 2 angiotensin II (T2-AT2) receptor and Mas-receptor pathways, which cause cardioprotective responses (eg, vasodilation, anti-inflammatory effects, and positive inotropic effects). ${ }^{82}$ Although $\sim 80 \%$ of patients received ACE inhibitors or T1-AT2 receptor blockers during EMPA-REG OUTCOME, empagliflozin could have had additive cardioprotective effects via non-classic RAAS pathways. ${ }^{82}$

\section{Renal effects}

Given the link between CVD and renal dysfunction in T2DM, ${ }^{83}$ renal effects are likely to influence $\mathrm{CV}$ outcomes. SGLT2 inhibition was shown to improve renal outcomes with empagliflozin in EMPA-REG OUTCOME. Specifically, reductions in relative risk for empagliflozin versus placebo groups were observed for incident or worsening nephropathy, progression to macroalbuminuria, doubling of serum creatinine levels, and initiation of renal replacement therapy. ${ }^{84}$ Renal outcomes were not viewed as statistically significant in the CANVAS Program, but potential renal benefits associated with canagliflozin versus placebo included decreased progression to albuminuria, and a reduction in the renal composite endpoint (sustained $40 \%$ reduction in eGFR, need for renal-replacement therapy, or renal death). ${ }^{24}$ The renal protection mechanisms are likely to be multifactorial; SGLT2 inhibition reduces proximal tubular sodium reabsorption and increases delivery of sodium to the macula densa, and it has been postulated that this may restore tubuloglomerular feedback, resulting in changes that decrease renal blood flow and reduce glomerular hyperfiltration and intraglomerular pressure ${ }^{81}$ Clinically, these effects may be manifested as acute reductions in albuminuria and eGFR, followed by longer term eGFR stability. ${ }^{85}$ However, it should be noted that the patient populations of these CVOTs were likely to be in the more advanced stages of diabetes (EMPA-REG OUTCOME, $57.0 \%$ and $25.1 \%$ of patients were diagnosed with T2DM for $>10$ years and $>5-10$ years, respectively; ${ }^{23}$ CANVAS Program, mean duration of T2DM was 13.5 years $^{24}$ ), thus glomerular hyperfiltration - which generally occurs early in the natural history of diabetes, before diabetic kidney disease progresses to its later stages, where glomerular filtration eventually decreases - would be less likely to occur.

\section{Inflammation}

The significance of inflammation in the development of atherosclerosis is well known, ${ }^{86}$ and diabetes is associated with systemic inflammation that causes endothelial dysfunction and contributes to atherosclerosis. ${ }^{87}$ However, as stated previously herein, the CV benefits observed during EMPA-REG OUTCOME do not appear presently to be closely related to effects on atherosclerosis. Nevertheless, experimental models have demonstrated that SGLT2 inhibition decreased expression of inflammatory markers in mouse plasma and liver tissue, ${ }^{88}$ and reduced oxidative stress associated with hyperglycemia in rat kidney and mouse aortic endothelium. ${ }^{89,90}$ This may be secondary to increased fatty acid oxidation caused by a shift in the substrate for energy metabolism (ie, from carbohydrate to lipid). However, the contribution of any potential anti-inflammatory actions of SGLT2 inhibitors on the effects observed during EMPA-REG OUTCOME is currently unknown, as clinical evidence is lacking. A preliminary clinical trial to investigate the role of empagliflozin on oxidative stress is underway. ${ }^{91}$

\section{Nitric oxide}

Increased oxidative stress and reduced nitric oxide bioavailability play a significant causal role in the endothelial dysfunction observed in patients with diabetes, ${ }^{92}$ which in turn contributes to the pathogenesis of atherosclerosis. ${ }^{92}$ Hyperglycemia and/or advanced glycosylation end products inhibit nitric oxide synthase, ${ }^{87,93,94}$ thus reducing the levels of nitric oxide and its protective effect against atherosclerosis. ${ }^{87}$ Improved glucose control in T2DM that is associated with SGLT2 inhibitor action and reduction in oxidative stress may help restore nitric oxide levels and have a favorable effect on $\mathrm{CV}$ outcomes. However, given that the benefits to $\mathrm{CV}$ risk observed during EMPA-REG OUTCOME do not currently appear to be closely related to effects on atherosclerosis, any potential effects pertaining to nitric oxide need further investigation.

\section{Glucagon effects}

Glucagon is known to regulate cardiac glucose utilization and modulate cardiac function with positive inotropic and anti-arrhythmogenic effects. ${ }^{95}$ Increased blood glucagon levels were associated with empagliflozin treatment, ${ }^{96}$ possibly due to the associated glucose excretion (as demonstrated in patients with T2DM using tracer techniques ${ }^{96}$ ) and/or 
potentially via a direct effect on pancreatic alpha cells (as elucidated from human and animal cell cultures ${ }^{97}$ ). It is possible that the reduced risks of heart failure and CV death reported during EMPA-REG OUTCOME may be partly explained by enhanced myocardial function and decreased rhythm disturbances, respectively, related to increased levels of glucagon. ${ }^{98}$

\section{SGLTI inhibition}

As SGLT2 inhibitors show some degree of binding to SGLT1 receptors, these agents could have an effect on tissue other than the kidney where SGLT1 expression occurs, such as the intestine, liver, lung, and heart. ${ }^{99}$ This is illustrated by the action of sotagliflozin, a first-in-class inhibitor of both SGLT2 and SGLT1, in which SGLT1 inhibition leads to a reduction in intestinal glucose absorption in addition to the increase in urinary glucose excretion mediated by SGLT2 inhibition (and, to a lesser extent, SGLT1 inhibition). ${ }^{100}$ Recent animal data suggest that SGLT1 provides an important protective mechanism against ischemia reperfusion injury by enhancing cardiac energy metabolism; ${ }^{101}$ hence, differences in cardiac SGLT1 selectivity may potentially explain the differences in mortality results between the CVOTs. Empagliflozin has relatively high selectivity for SGLT2 over SGLT1 and, therefore, should not inhibit SGLT1 (inhibitor concentration at half-maximal response [nM]: empagliflozin, 3.1 for SGLT2 and 8300 for SGLT1 [ $>2500$-fold selectivity]; dapagliflozin, 1.2 for SGLT2 and 1400 for SGLT1 [>1200-fold selectivity]; canagliflozin, 2.7 for SGLT2 and 710 for SGLT1 [>250-fold selectivity $]^{102}$ ).

\section{Conclusion}

Recently reported CVOTs involving canagliflozin and other CV outcomes data for SGLT2 inhibitors support the CV benefits of these agents in T2DM, as originally observed with empagliflozin during the EMPA-REG OUTCOME trial. In view of the relatively short time in which $\mathrm{CV}$ benefits were demonstrated during EMPA-REG OUTCOME, the underlying process appears to be unrelated to changes in the development or progression of atherosclerosis. Most clinical commentators agree that the mechanism is likely to be multifactorial and may include hemodynamic effects, such as reductions in BP and intravascular volume, as well as metabolic effects, such as changes in adiposity and fuel energetics. Other factors may warrant further investigation, such as possible effects on inflammation and nitric oxide, as well as potential $\mathrm{CV}$ and metabolic effects of increased glucagon release. Additional studies to determine whether
SGLT2 inhibitors have a broader role in the treatment of heart failure are underway, as are studies to investigate the role of these agents in atherosclerosis (Table 5) ${ }^{103}$ However, further questions may now arise following a recent exploratory investigation into potential mediators of the reduction in risk of $\mathrm{CV}$ death with empagliflozin versus placebo during the EMPA-REG OUTCOME trial, in which it was reported that changes in some traditional $\mathrm{CV}$ risk factors (including obesity, BP, lipids, and renal function) made negligible contributions, whereas changes in volume-related factors (hematocrit and hemoglobin) appeared to be important mediators of the reduction in CV mortality risk. ${ }^{76}$ Furthermore, although alluded to in the CANVAS Program and CVD-REAL trials, dedicated randomized controlled studies to investigate the

Table 5 Clinical trials of sodium glucose cotransporter 2 inhibitors that are underway to investigate heart failure or atherosclerosis

\begin{tabular}{|c|c|}
\hline $\begin{array}{l}\text { Agent and } \\
\text { indication }\end{array}$ & $i l s^{a}$ \\
\hline $\begin{array}{l}\text { Canagliflozin + } \\
\text { heart failure }\end{array}$ & $\begin{array}{l}\text { Treatment of Diabetes in Patients With Systolic Heart } \\
\text { Failure } \\
\text { https://clinicaltrials.gov/ct2/show/NCT029209/8 }\end{array}$ \\
\hline $\begin{array}{l}\text { Dapagliflozin + } \\
\text { heart failure }\end{array}$ & $\begin{array}{l}\text { Dapagliflozin in Type } 2 \text { Diabetes or Pre-diabetes, } \\
\text { and PRESERVED Ejection Fraction Heart Failure } \\
\text { (PRESERVED-HF) } \\
\text { https://clinicaltrials.gov/ct2/show/NCT03030235 } \\
\text { Study to Evaluate the Effect of Dapagliflozin on } \\
\text { the Incidence of Worsening Heart Failure or } \\
\text { Cardiovascular Death in Patients With Chronic Heart } \\
\text { Failure (Dapa-HF) } \\
\text { https://clinicaltrials.gov/ct2/show/NCT03036I24 } \\
\text { Dapagliflozin Effect on Symptoms and Biomarkers in } \\
\text { Diabetes Patients With Heart Failure (DEFINE-HF) } \\
\text { https://clinicaltrials.gov/ct2/show/NCT02653482 } \\
\text { Safety and Effectiveness of SGLT-2 Inhibitors in Patients } \\
\text { With Heart Failure and Diabetes (REFORM) } \\
\text { https://clinicaltrials.gov/ct2/show/NCT0239742I }\end{array}$ \\
\hline $\begin{array}{l}\text { Empagliflozin + } \\
\text { heart failure }\end{array}$ & $\begin{array}{l}\text { EMPagliflozin outcomE tRial in Patients With chrOnic } \\
\text { heaRt Failure With Reduced Ejection Fraction } \\
\text { (EMPEROR-Reduced) } \\
\text { https://clinicaltrials.gov/ct2/show/NCT03057977 } \\
\text { EMPagliflozin outcomE tRial in Patients With chrOnic } \\
\text { heaRt Failure With Preserved Ejection Fraction } \\
\text { (EMPEROR-Preserved) } \\
\text { https://clinicaltrials.gov/ct2/show/NCT0305795I }\end{array}$ \\
\hline $\begin{array}{l}\text { Dapagliflozin + } \\
\text { atherosclerosis }\end{array}$ & $\begin{array}{l}\text { Effect of Dapagliflozin on Vascular Functions in Patients } \\
\text { With Type } 2 \text { Diabetes Compared to Gliclazide } \\
\text { https://clinicaltrials.gov/ct2/show/NCT02610088 }\end{array}$ \\
\hline $\begin{array}{l}\text { Empagliflozin }+ \\
\text { atherosclerosis }\end{array}$ & $\begin{array}{l}\text { Rationale and design of a multicenter placebo- } \\
\text { controlled double-blind randomized trial to evaluate } \\
\text { the effect of empagliflozin on endothelial function: the } \\
\text { EMBLEM trial' } \\
\text { Unique Trial Number (Japan): UMIN000024502 }\end{array}$ \\
\hline
\end{tabular}

Note: a Clinical trial registry website (US National Institutes of Health); citation listed if study details have been published. 
effect of SGLT2 inhibitors in the primary prevention of CVD are also needed. Clinicians await the results from further CVOTs of SGLT2 inhibitors, which when published will add to the evidence base in determining the clinical role of this drug class in reducing CV risk in patients with T2DM.

\section{Author contributions}

All authors contributed toward data analysis, drafting and critically revising the paper and agree to be accountable for all aspects of the work.

\section{Disclosure}

T.S.C. receives speaker's bureau and/or consultant fees from Dexcom, Sanofi, Novo Nordisk, and Valeritas. J.P. receives speaker's bureau fees and consulting fees from Insulet, Sanofi, and Valeritas, and consulting fees from Dexcom, MannKind, and Novo Nordisk. Medical writing assistance, supported financially by Boehringer Ingelheim Pharmaceuticals, Inc. (BIPI), was provided by Geraldine Thompson, $\mathrm{PhD}$, Jennifer Garrett, MB BS, and Debra Brocksmith, MB ChB, $\mathrm{PhD}$, of Envision Scientific Solutions during the preparation of this manuscript. BIPI was given the opportunity to review the data used in the manuscript for factual accuracy only. The authors report no other conflicts of interest in this work.

\section{References}

1. American Diabetes Association. 9. Cardiovascular disease and risk management. Diabetes Care. 2017;40 (Suppl 1):S75-S87.

2. UK Prospective Diabetes Study (UKPDS) Group. Intensive bloodglucose control with sulphonylureas or insulin compared with conventional treatment and risk of complications in patients with type 2 diabetes (UKPDS 33). Lancet. 1998;352(9131):837-853. Erratum: Lancet. 1999;354(9178):602.

3. Holman RR, Paul SK, Bethel MA, Matthews DR, Neil HA. 10-year follow-up of intensive glucose control in type 2 diabetes. $N$ Engl J Med. 2008;359(15):1577-1589.

4. Skyler JS, Bergenstal R, Bonow RO, et al. Intensive glycemic control and the prevention of cardiovascular events: implications of the ACCORD, ADVANCE, and VA diabetes trials: a position statement of the American Diabetes Association and a scientific statement of the American College of Cardiology Foundation and the American Heart Association. Diabetes Care. 2009;32(1):187-192.

5. Action to Control Cardiovascular Risk in Diabetes Study Group, Gerstein HC, Miller ME, Byington RP, et al. Effects of intensive glucose lowering in type 2 diabetes. $N$ Engl J Med. 2008;358(24): 2545-2559.

6. ADVANCE Collaborative Group, Patel A, MacMahon S, Chalmers J, et al. Intensive blood glucose control and vascular outcomes in patients with type 2 diabetes. N Engl J Med. 2008;358(24):2560-2572.

7. Duckworth W, Abraira C, Moritz T, et al; VADT Investigators. Glucose control and vascular complications in veterans with type 2 diabetes. N Engl J Med. 2009;360(2):129-139.

8. ACCORD Study Group, Gerstein HC, Miller ME, Genuth S, et al. Long-term effects of intensive glucose lowering on cardiovascular outcomes. N Engl J Med. 2011;364(9):818-828.
9. Giorgino F, Home PD, Tuomilehto J. Glucose control and vascular outcomes in type 2 diabetes: is the picture clear? Diabetes Care. 2016;39(Suppl 2):S187-S195.

10. Nissen SE, Wolski K. Effect of rosiglitazone on the risk of myocardial infarction and death from cardiovascular causes. $N$ Engl J Med. 2007;356(24):2457-2471. Erratum: N Engl J Med. 2007;357(1):100.

11. Food and Drug Administration. Guidance for industry: diabetes mellitus-evaluating cardiovascular risk in new antidiabetic therapies to treat type 2 diabetes. Available from: http://www.fda.gov/downloads/drugs/guidancecomplianceregulatoryinformation/guidances/ ucm071627.pdf. Accessed February 22, 2017.

12. Singh AK, Singh R. SAVOR-TIMI to SUSTAIN-6: a critical comparison of cardiovascular outcome trials of antidiabetic drugs. Expert Rev Clin Pharmacol. 2017;10(4):429-442.

13. Scirica BM, Bhatt DL, Braunwald E, et al; SAVOR-TIMI 53 Steering Committee and Investigators. Saxagliptin and cardiovascular outcomes in patients with type 2 diabetes mellitus. $N$ Engl J Med. 2013;369(14):1317-1326.

14. White WB, Cannon CP, Heller SR, et al; EXAMINE Investigators. Alogliptin after acute coronary syndrome in patients with type 2 diabetes. N Engl J Med. 2013;369(14):1327-1335.

15. Green JB, Bethel MA, Armstrong PW, et al; TECOS Study Group. Effect of sitagliptin on cardiovascular outcomes in type 2 diabetes. $N$ Engl J Med. 2015;373(3):232-242.

16. Pfeffer MA, Claggett B, Diaz R, et al; ELIXA Investigators. Lixisenatide in patients with type 2 diabetes and acute coronary syndrome. $N$ Engl J Med. 2015;373(23):2247-2257.

17. Marso SP, Daniels GH, Brown-Frandsen K, et al; LEADER Steering Committee; LEADER Trial Investigators. Liraglutide and cardiovascular outcomes in type 2 diabetes. $N$ Engl J Med. 2016;375(4): 311-322.

18. Marso SP, Bain SC, Consoli A, et al; SUSTAIN-6 Investigators. Semaglutide and cardiovascular outcomes in patients with type 2 diabetes. N Engl J Med. 2016;375(19):1834-1844.

19. Holman RR, Bethel MA, Mentz RJ, et al; EXSCEL Study Group. Effects of once-weekly exenatide on cardiovascular outcomes in type 2 diabetes. N Engl J Med. 2017;377(13):1228-1239.

20. Fellner C. Novel treatments target type-2 diabetes. $P$ T. 2016;41(10): 650-653.

21. Marso SP, McGuire DK, Zinman B, et al; DEVOTE Study Group. Efficacy and safety of degludec versus glargine in type 2 diabetes. $N$ Engl J Med. 2017;377(8):723-732.

22. Vaccaro O, Masulli M, Nicolucci A, et al; Thiazolidinediones Or Sulfonylureas Cardiovascular Accidents Intervention Trial (TOSCA. IT) study group; Italian Diabetes Society. Effects on the incidence of cardiovascular events of the addition of pioglitazone versus sulfonylureas in patients with type 2 diabetes inadequately controlled with metformin (TOSCA.IT): a randomised, multicentre trial. Lancet Diabetes Endocrinol. 2017;5(11):887-897.

23. Zinman B, Wanner C, Lachin JM, et al; EMPA-REG OUTCOME Investigators. Empagliflozin, cardiovascular outcomes, and mortality in type 2 diabetes. $N$ Engl J Med. 2015;373(22):2117-2128.

24. Neal B, Perkovic V, Mahaffey KW, et al; CANVAS Program Collaborative Group. Canagliflozin and cardiovascular and renal events in type 2 diabetes. N Engl J Med. 2017;377(7):644-657.

25. Kosiborod M, Cavender MA, Fu AZ, et al; CVD-REAL Investigators and Study Group. Lower risk of heart failure and death in patients initiated on sodium-glucose cotransporter-2 inhibitors versus other glucose-lowering drugs: the CVD-REAL study (Comparative effectiveness of cardiovascular outcomes in new users of sodium-glucose cotransporter-2 inhibitors). Circulation. 2017;136(3):249-259.

26. Birkeland KI, Jorgensen ME, Carstensen B, et al. Cardiovascular mortality and morbidity in patients with type 2 diabetes following initiation of sodium-glucose co-transporter-2 inhibitors versus other glucose-lowering drugs (CVD-REAL Nordic): a multinational observational analysis. Lancet Diabetes Endocrinol. 2017;5(9):709-717. 
27. Marx N, Rosenstock J, Kahn SE, et al. Design and baseline characteristics of the CARdiovascular Outcome Trial of LINAgliptin Versus Glimepiride in Type 2 Diabetes (CAROLINA ${ }^{\circledR}$ ). Diab Vasc Dis Res. 2015;12(3):164-174.

28. Jardine MJ, Mahaffey KW, Neal B, et al; CREDENCE study investigators. The canagliflozin and renal endpoints in diabetes with established nephropathy clinical evaluation (CREDENCE) study rationale, design, and baseline characteristics. Am J Nephrol. 2017;46(6):462-472.

29. Novo Nordisk US. Victoza ${ }^{\circledR}$ (liraglutide) is approved in the US as the only type 2 diabetes treatment indicated to reduce the risk of three major adverse cardiovascular events. Available from: http://press. novonordisk-us.com/2017-08-25-Victoza-R-liraglutide-is-approvedin-the-US-as-the-only-type-2-diabetes-treatment-indicated-to-reducethe-risk-of-three-major-adverse-cardiovascular-events. Accessed October 11, 2017.

30. CardioBrief. Clinical trial expert's deep dive into the important new liraglutide trial. Available from: http://www.cardiobrief. org/2016/06/13/clinical-trial-experts-deep-dive-into-the-importantnew-liraglutide-trial/. Accessed October 11, 2017.

31. Abdul-Ghani M, Del Prato S, Chilton R, DeFronzo RA. SGLT2 inhibitors and cardiovascular risk: lessons learned from the EMPA-REG OUTCOME study. Diabetes Care. 2016;39(5):717-725.

32. Pitt B, Remme W, Zannad F, et al; Eplerenone Post-Acute Myocardial Infarction Heart Failure Efficacy and Survival Study Investigators. Eplerenone, a selective aldosterone blocker, in patients with left ventricular dysfunction after myocardial infarction. $N$ Engl J Med. 2003;348(14):1309-1321.

33. Fitchett D, Zinman B, Wanner C, et al; EMPA-REG OUTCOME ${ }^{\circledR}$ trial investigators. Heart failure outcomes with empagliflozin in patients with type 2 diabetes at high cardiovascular risk: results of the EMPAREG OUTCOME ${ }^{\circledR}$ trial. Eur Heart J. 2016;37(19):1526-1534.

34. Raz I, Cahn A. Heart failure: SGLT2 inhibitors and heart failure clinical implications. Nat Rev Cardiol. 2016;13(4):185-186.

35. Baartscheer A, Schumacher CA, Wust RC, et al. Empagliflozin decreases myocardial cytoplasmic $\mathrm{Na}+$ through inhibition of the cardiac $\mathrm{Na}+\mathrm{H}+$ exchanger in rats and rabbits. Diabetologia. 2017;60(3): 568-573.

36. Verma S, Garg A, Yan AT, et al. Effect of empagliflozin on left ventricular mass and diastolic function in individuals with diabetes: an important clue to the EMPA-REG OUTCOME trial? Diabetes Care. 2016;39(12):e212-e213.

37. Tucker ME. CANVAS: experts spar on canagliflozin risk/benefit in diabetes. Available from: http://www.medscape.com/viewarticle/881719. Accessed July 10, 2017.

38. Schilsky RL. Finding the evidence in real-world evidence: moving from data to information to knowledge. J Am Coll Surg. 2017;224(1):1-7.

39. Fitchett D. SGLT2 inhibitors in the real world: too good to be true? Lancet Diabetes Endocrinol. 2017;5(9):673-675.

40. Vallon V. The mechanisms and therapeutic potential of SGLT2 inhibitors in diabetes mellitus. Annu Rev Med. 2015;66:255-270.

41. Vestri S, Okamoto MM, de Freitas HS, et al. Changes in sodium or glucose filtration rate modulate expression of glucose transporters in renal proximal tubular cells of rat. J Membr Biol. 2001;182(2):105-112.

42. Tabatabai NM, Sharma M, Blumenthal SS, Petering DH. Enhanced expressions of sodium-glucose cotransporters in the kidneys of diabetic Zucker rats. Diabetes Res Clin Pract. 2009;83(1):e27-e30.

43. STEGLATRO ${ }^{\mathrm{TM}}$ (ertugliflozin) tablets, for oral use [prescribing information]. Kenilworth, NJ: Merck Sharp \& Dohme Corp; 2018. Available from: https:/www.accessdata.fda.gov/drugsatfda_docs/ label/2017/209803s000lbl.pdf. Accessed January 3, 2018.

44. Storgaard H, Gluud LL, Bennett C, et al. Benefits and harms of sodium-glucose co-transporter 2 inhibitors in patients with type 2 diabetes: a systematic review and meta-analysis. PLoS One. 2016;11(11):e0166125.

45. Scheen AJ. Reduction in cardiovascular and all-cause mortality in the EMPA-REG OUTCOME trial: a critical analysis. Diabetes Metab. 2016;42(2):71-76.
46. Heise T, Seewaldt-Becker E, Macha S, et al. Safety, tolerability, pharmacokinetics and pharmacodynamics following 4 weeks' treatment with empagliflozin once daily in patients with type 2 diabetes. Diabetes Obes Metab. 2013;15(7):613-621.

47. Cefalu WT, Leiter LA, Yoon KH, et al. Efficacy and safety of canagliflozin versus glimepiride in patients with type 2 diabetes inadequately controlled with metformin (CANTATA-SU): 52 week results from a randomised, double-blind, phase 3 non-inferiority trial. Lancet. 2013;382(9896):941-950.

48. Bolinder J, Ljunggren Ö, Johansson L, et al. Dapagliflozin maintains glycaemic control while reducing weight and body fat mass over 2 years in patients with type 2 diabetes mellitus inadequately controlled on metformin. Diabetes Obes Metab. 2014;16(2):159-169.

49. Ridderstråle M, Andersen KR, Zeller C, Kim G, Woerle HJ, Broedl UC; EMPA-REG H2H-SU trial investigators. Comparison of empagliflozin and glimepiride as add-on to metformin in patients with type 2 diabetes: a 104-week randomised, active-controlled, double-blind, phase 3 trial. Lancet Diabetes Endocrinol. 2014;2(9):691-700.

50. Ferrannini E, Baldi S, Frascerra S, et al. Shift to fatty substrate utilization in response to sodium-glucose cotransporter 2 inhibition in subjects without diabetes and patients with type 2 diabetes. Diabetes. 2016;65(5):1190-1195.

51. Després JP, Lemieux I. Abdominal obesity and metabolic syndrome. Nature. 2006;444(7121):881-887.

52. Lee MJ, Wu Y, Fried SK. Adipose tissue heterogeneity: implication of depot differences in adipose tissue for obesity complications. Mol Aspects Med. 2013;34(1):1-11.

53. Daniele G, Xiong J, Solis-Herrera C, et al. Dapagliflozin enhances fat oxidation and ketone production in patients with type 2 diabetes. Diabetes Care. 2016;39(11):2036-2041.

54. Cahill GF Jr, Veech RL. Ketoacids? Good medicine? Trans Am Clin Climatol Assoc. 2003;114:149-161; discussion 162-163.

55. Sato K, Kashiwaya Y, Keon CA, et al. Insulin, ketone bodies, and mitochondrial energy transduction. FASEB J. 1995;9(8):651-658.

56. Tahara A, Kurosaki E, Yokono M, et al. Effects of sodium-glucose cotransporter 2 selective inhibitor ipragliflozin on hyperglycaemia, oxidative stress, inflammation and liver injury in streptozotocin-induced type 1 diabetic rats. J Pharm Pharmacol. 2014;66(7):975-987.

57. Mudaliar S, Alloju S, Henry RR. Can a shift in fuel energetics explain the beneficial cardiorenal outcomes in the EMPA-REG OUTCOME study? A unifying hypothesis. Diabetes Care. 2016;39(7):1115-1122.

58. Ferrannini E, Mark M, Mayoux E. CV protection in the EMPA-REG OUTCOME trial: a "thrifty substrate" hypothesis. Diabetes Care. 2016;39(7):1108-1114.

59. Xiong W, Xiao MY, Zhang M, Chang F. Efficacy and safety of canagliflozin in patients with type 2 diabetes: A meta-analysis of randomized controlled trials. Medicine (Baltimore). 2016;95(48):e5473.

60. Kohler S, Zeller C, Iliev H, Kaspers S. Safety and tolerability of empagliflozin in patients with type 2 diabetes: pooled analysis of phase I-III clinical trials. Adv Ther. 2017;34(7):1707-1726.

61. Haas B, Eckstein N, Pfeifer V, Mayer P, Hass MDS. Efficacy, safety and regulatory status of SGLT2 inhibitors: focus on canagliflozin. Nutr Diabetes. 2014;4(11):e143.

62. Briand F, Mayoux E, Brousseau E, et al. Empagliflozin, via switching metabolism toward lipid utilization, moderately increases LDL cholesterol levels through reduced LDL catabolism. Diabetes. 2016;65(7):2032-2038.

63. Wu AH, Gladden JD, Ahmed M, Ahmed A, Filippatos G. Relation of serum uric acid to cardiovascular disease. Int J Cardiol. 2016;213:4-7.

64. Cheeseman C. Solute carrier family 2, member 9 and uric acid homeostasis. Curr Opin Nephrol Hypertens. 2009;18(5):428-432.

65. Inzucchi SE, Zinman B, Wanner C, et al. SGLT-2 inhibitors and cardiovascular risk: proposed pathways and review of ongoing outcome trials. Diab Vasc Dis Res. 2015;12(2):90-100.

66. Tikkanen I, Chilton R, Johansen OE. Potential role of sodium glucose cotransporter 2 inhibitors in the treatment of hypertension. Curr Opin Nephrol Hypertens. 2016;25(2):81-86. 
67. Tikkanen I, Narko K, Zeller C, et al; EMPA-REG BP Investigators. Empagliflozin reduces blood pressure in patients with type 2 diabetes and hypertension. Diabetes Care. 2015;38(3):420-428.

68. Townsend RR, Machin I, Ren J, et al. Reductions in mean 24-hour ambulatory blood pressure after 6-week treatment with canagliflozin in patients with type 2 diabetes mellitus and hypertension. $J$ Clin Hypertens (Greenwich). 2016;18(1):43-52.

69. Weber MA, Mansfield TA, Cain VA, Iqbal N, Parikh S, Ptaszynska A. Blood pressure and glycaemic effects of dapagliflozin versus placebo in patients with type 2 diabetes on combination antihypertensive therapy: a randomised, double-blind, placebo-controlled, phase 3 study. Lancet Diabetes Endocrinol. 2016;4(3):211-220.

70. Cook NR, Cohen J, Hebert PR, Taylor JO, Hennekens CH. Implications of small reductions in diastolic blood pressure for primary prevention Arch Intern Med. 1995;155(7):701-709.

71. Hardy ST, Loehr LR, Butler KR, et al. Reducing the blood pressurerelated burden of cardiovascular disease: impact of achievable improvements in blood pressure prevention and control. J Am Heart Assoc. 2015;4(10):e002276.

72. Lambers Heerspink HJ, de Zeeuw D, Wie L, Leslie B, List J. Dapagliflozin a glucose-regulating drug with diuretic properties in subjects with type 2 diabetes. Diabetes Obes Metab. 2013;15(9):853-862.

73. Kimura G. Importance of inhibiting sodium-glucose cotransporter and its compelling indication in type 2 diabetes: pathophysiological hypothesis. J Am Soc Hypertens. 2016;10(3):271-278.

74. Cefalu WT, Stenlöf K, Leiter LA, et al. Effects of canagliflozin on body weight and relationship to HbA1c and blood pressure changes in patients with type 2 diabetes. Diabetologia. 2015;58(6):1183-1187.

75. Cherney DZ, Perkins BA, Soleymanlou N, et al. The effect of empagliflozin on arterial stiffness and heart rate variability in subjects with uncomplicated type 1 diabetes mellitus. Cardiovasc Diabetol. 2014;13:28

76. Inzucchi SE, Zinman B, Fitchett D, et al. How does empagliflozin reduce cardiovascular mortality? Insights from a mediation analysis of the EMPA-REG OUTCOME trial. Diabetes Care. 2018;41(2): 356-363.

77. Scheen AJ. Reappraisal of the diuretic effect of empagliflozin in the EMPA-REG OUTCOME trial: comparison with classic diuretics. Diabetes Metab. 2016;42(4):224-233.

78. Marx N, McGuire DK. Sodium-glucose cotransporter-2 inhibition for the reduction of cardiovascular events in high-risk patients with diabetes mellitus. Eur Heart J. 2016;37(42):3192-3200.

79. Mudaliar S, Polidori D, Zambrowicz B, Henry RR. Sodium-glucose cotransporter inhibitors: effects on renal and intestinal glucose transport: from bench to bedside. Diabetes Care. 2015;38(12): 2344-2353.

80. Sano M, Takei M, Shiraishi Y, Suzuki Y. Increased hematocrit during sodium-glucose cotransporter 2 inhibitor therapy indicates recovery of tubulointerstitial function in diabetic kidneys. J Clin Med Res. 2016;8(12):844-847.

81. Cherney DZ, Perkins BA, Soleymanlou N, et al. Renal hemodynamic effect of sodium-glucose cotransporter 2 inhibition in patients with type 1 diabetes mellitus. Circulation. 2014;129(5):587-597.

82. Muskiet MH, van Raalte DH, van Bommel EJ, Smits MM, Tonneijck L. Understanding EMPA-REG OUTCOME. Lancet Diabetes Endocrinol. 2015;3(12):928-929.

83. Wang Y, Katzmarzyk PT, Horswell R, Zhao W, Johnson J, Hu G. Kidney function and the risk of cardiovascular disease in patients with type 2 diabetes. Kidney Int. 2014;85(5):1192-1199.

84. Wanner C, Inzucchi SE, Lachin JM, et al; EMPA-REG OUTCOME Investigators. Empagliflozin and progression of kidney disease in type 2 diabetes. N Engl J Med. 2016;375(4):323-334.
85. Heerspink HJ, Desai M, Jardine M, Balis D, Meininger G, Perkovic V. Canagliflozin slows progression of renal function decline independently of glycemic effects. J Am Soc Nephrol. 2017;28(1):368-375.

86. Ross R. Atherosclerosis-an inflammatory disease. $N$ Engl J Med. 1999;340(2):115-126.

87. Beckman JA, Creager MA, Libby P. Diabetes and atherosclerosis: epidemiology, pathophysiology, and management. JAMA. 2002;287(19):2570-2581.

88. Tahara A, Kurosaki E, Yokono M, et al. Effects of SGLT2 selective inhibitor ipragliflozin on hyperglycemia, hyperlipidemia, hepatic steatosis, oxidative stress, inflammation, and obesity in type 2 diabetic mice. Eur J Pharmacol. 2013;715(1-3):246-255.

89. Osorio H, Coronel I, Arellano A, et al. Sodium-glucose cotransporter inhibition prevents oxidative stress in the kidney of diabetic rats. Oxid Med Cell Longev. 2012;2012:542042.

90. Salim HM, Fukuda D, Yagi S, Soeki T, Shimabukuro M, Sata M. Glycemic control with ipragliflozin, a novel selective SGLT2 inhibitor, ameliorated endothelial dysfunction in streptozotocin-induced diabetic mouse. Front Cardiovasc Med. 2016;3:43.

91. Larsen EL, Cejvanovic V, Kjaer LK, et al. The effect of empagliflozin on oxidative nucleic acid modifications in patients with type 2 diabetes: protocol for a randomised, double-blinded, placebo-controlled trial BMJ Open. 2017;7(5):e014728.

92. Tabit CE, Chung WB, Hamburg NM, Vita JA. Endothelial dysfunction in diabetes mellitus: molecular mechanisms and clinical implications. Rev Endocr Metab Disord. 2010;11(1):61-74.

93. Goligorsky MS, Chen J, Brodsky S. Workshop: endothelial cell dysfunction leading to diabetic nephropathy: focus on nitric oxide. Hypertension. 2001;37(2 Pt 2):744-748

94. Chu S, Bohlen HG. High concentration of glucose inhibits glomerular endothelial eNOS through a PKC mechanism. Am J Physiol Renal Physiol. 2004;287:F384-F392.

95. Jones BJ, Tan T, Bloom SR. Minireview: glucagon in stress and energy homeostasis. Endocrinology. 2012;153(3):1049-1054.

96. Ferrannini E, Muscelli E, Frascerra S, et al. Metabolic response to sodium-glucose cotransporter 2 inhibition in type 2 diabetic patients. J Clin Invest. 2014;124(2):499-508.

97. Bonner C, Kerr-Conte J, Gmyr V, et al. Inhibition of the glucose transporter SGLT2 with dapagliflozin in pancreatic alpha cells triggers glucagon secretion. Nat Med. 2015;21(5):512-517.

98. Ceriello A, Genovese S, Mannucci E, Gronda E. Glucagon and heart in type 2 diabetes: new perspectives. Cardiovasc Diabetol. 2016;15(1):123.

99. Wright EM, Loo DD, Hirayama BA. Biology of human sodium glucose transporters. Physiol Rev. 2011;91(2):733-794.

100. Cariou B, Charbonnel B. Sotagliflozin as a potential treatment for type 2 diabetes mellitus. Expert Opin Investig Drugs. 2015;24(12):1647-1656.

101. Kashiwagi Y, Nagoshi T, Yoshino T, et al. Expression of SGLT1 in human hearts and impairment of cardiac glucose uptake by phlorizin during ischemia-reperfusion injury in mice. PLoS One. 2015;10(6):e0130605.

102. Grempler R, Thomas L, Eckhardt M, et al. Empagliflozin, a novel selective sodium glucose cotransporter-2 (SGLT-2) inhibitor: characterisation and comparison with other SGLT-2 inhibitors. Diabetes Obes Metab. 2012;14(1):83-90.

103. Tanaka A, Shimabukuro M, Okada Y, et al; EMBLEM Trial Investigators. Rationale and design of a multicenter placebo-controlled double-blind randomized trial to evaluate the effect of empagliflozin on endothelial function: the EMBLEM trial. Cardiovasc Diabetol. 2017;16(1):48. 
Diabetes, Metabolic Syndrome and Obesity: Targets and Therapy is an international, peer-reviewed open-access journal committed to the rapid publication of the latest laboratory and clinical findings in the fields of diabetes, metabolic syndrome and obesity research. Original research, review, case reports, hypothesis formation, expert opinion and commentaries are all considered for publication. The manuscript management system is completely online and includes a very quick and fair peer-review system, which is all easy to use. Visit http://www.dovepress.com/testimonials.php to read real quotes from published authors.

Submit your manuscript here: https://www.dovepress.com/diabetes-metabolic-syndrome-and-obesity-targets-and-therapy-journal 